\title{
En las manos de Astarté, \\ La abrasadora
}

ANA M VAZQUEZ HOYS

Departamento Prehistoria e $H^{*}$ Antigua, UNED

En el curso de la extensión fenicia por el Mediterráneo, hacia los siglos IX-VIII a. C., debió llevarse a cabo el primer asentamiento fenicio en la actual ciudad de Melilla, que estos días nos acoge, como nuevos navegantes del presente, conmemorando otras efemérides, más cercanas en el tiempo.

"La de los muchos nombres" podríamos denominar a esta bella tierra, que en un principio recibió el fenicio de Rusadir, aludiendo, como otros muchos puntos del Mediterráneo, al promontorio que la protege, el cabo Tres Forcas, el cabo importante o poderoso, también denominada Metagonio en griego o Melitta, Melilla, más posterior.

La escasez de documentos arqueológicos que nos permitan conocer con fiabilidad el verdadero comienzo de la colonización fenicia de Occidente y con ella de Rusadir, corre pareja con otras muchas incógnitas que plantean las más antiguas navegaciones por el Mediterráneo del pueblo fenicio y de los problemas que producen la escasez de noticias referentes a este pueblo.

De este problema y de los comienzos de la navegación por el Mediterráneo nos hablará estos días el Dr. Victor Guerrero Ayuso, ya que a ello ha 
dedicado gran parte de su vida y casi la totalidad de su vida académica e investigadora. Bástenos a nosotros decir que, de todos los estudiosos y amantes del mundo antiguo es ya sabido que las fechas más cercanas que se barajaban hace unos años para la colonización fenicia de Occidente, el siglo VIII a. C., hace tiempo que se ha descartado.

Las navegaciones hacia el extremo Occidente, al menos durante gran parte del II milenio, desde la costa cananea y el Mediterráneo oriental, no sólo se han mostrado posibles a nivel especulativo sino que están probadas arqueológicamente.

Y la aparición de materiales cerámicos micénicos en Montoro, en la parte superios de la cuenca del Guadalquivir, además de otras muchas evidencias, como el altar de cuernos de La Encantada (Ciudad Real), correspondiente al Bronce Medio o el de El Oficio (Almería), nos permiten afirmarlas. Y están probadas, sobre todo, como ya escribimos hace varios años, por la "extraña" similitud en los enterramientos en una y otra orilla del Mediterráneo durante el II milenio.

Estas y otras muchas pruebas nos han permitido llegar a la conclusión de la existencia de la denominada "precolonización" de las costas del extremo occidental del Mediterráneo, tanto en su orilla africana como europea, en el II milenio a. C. por parte de los navegantes orientales, en épocas muchos más antiguas a las que, en un momento determinado, y a partir del siglo VIII, se encuentran ya plenamente asentados en el norte de Africa y en el sur de la Península Ibérica (1). Es decir, y para los que nos escuchan y no sepan de qué fechas estamos hablando: Durante muchos años se ha dudado de que Cádiz fuese fundada en el 1. 100 a. C., porque se pensaba que los orientales, cananeos, egipcios, egeos, anatolios, o bién no tenían técnicas de navegación que les permitiese llegar a Occidente, o bién no tenían motivos que provocasen la necesidad de hacerlo. Y que las primeras navegaciones hacia Occidente, por parte de los cananeos, anatolios o egipcios, o los denominados fenicios, no comenzaron antes del siglo VIII, porque, al excavar, los materiales fenicios más antiguos solamente se remontan hasta esa fecha, negándose la validez cronológica de otras evidencias materiales. 
Pues bién: Demostrada ya la posibilidad de estas antiguas navegaciones y la antiquísima presencia de gentes orientales en el extremo Occidente del Mediterráneo, a nadie puede extrañar la inclusión de la actual Melilla en un circuito económico que comprendía, en último término, el denominado Círculo del Estrecho, aludiendo a la unidad socio-económica y cultural de tal área.

De la potencia económica de este ámbito, basada, sobre todo en los tres productos capitales de la economía fenicia: Sal y salazones, púrpura y miel, se ha ocupado la Dra. Fernández Uriel, que nos ha reunido en este Acto y a quien agradezco su invitación para participar en él, así como al Centro Asociado de la UNED de Melilla, a los que felicito por esta iniciativa.

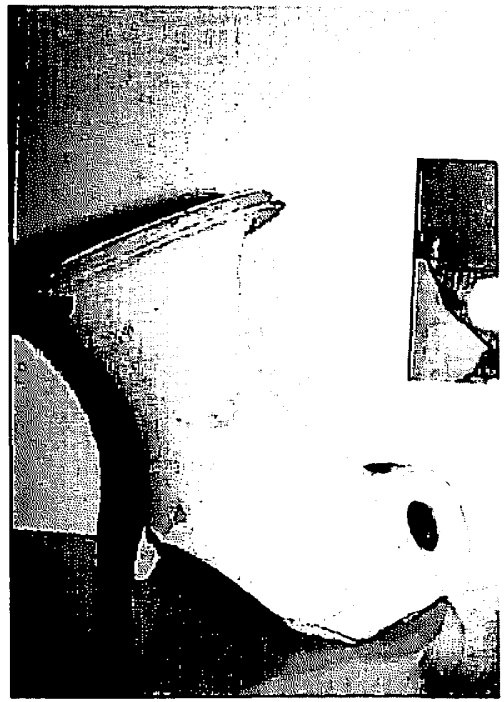

FIC:URA

lirugnento de ánfora con una iesseripcion puiniea. Museo de Melilla

Nuestra exposición tiene un título, basado en una inscripción fenicio-púnica: BOB ASTART, de un fragmento de ánfora conservado en el Museo de esta ciudad (figura 1) que alguien tradujo "En las manos de Astarté". La segunda parte del título me ha sido sugerida por la lectura del artículo de Enrique Gonzalves Gravioto sobre la economía antigua de Melilla que tiene Vds. citado en la Bibliografía y un comentario del sr. Fernandez de Castro sobre Melilla prehispánica. En este libro se alude a la significación posible del término árabe Malila, que originaría el nombre actual de Melilla, como "calor producido por la fiebre" o, "abrasadora" o decía también el arabista Juan Márquez que dicho término podría convertirse en "Mellosa", que equivaldría a "Maga" (adoradora del fuego)", aunque no me resigno a pensar que dicho término no tenga nada que ver con la miel y el valor místico, mágico y religioso que tenía en la Antigüedad.

Tal vez podamos llegar, por medio de la imaginación, a reunir miel y magia, miel e inmortalidad y lleguemos a la conclusión de que ambas, miel y magia y también Astarté tienen mucho que ver en la pequeña o gran his- 


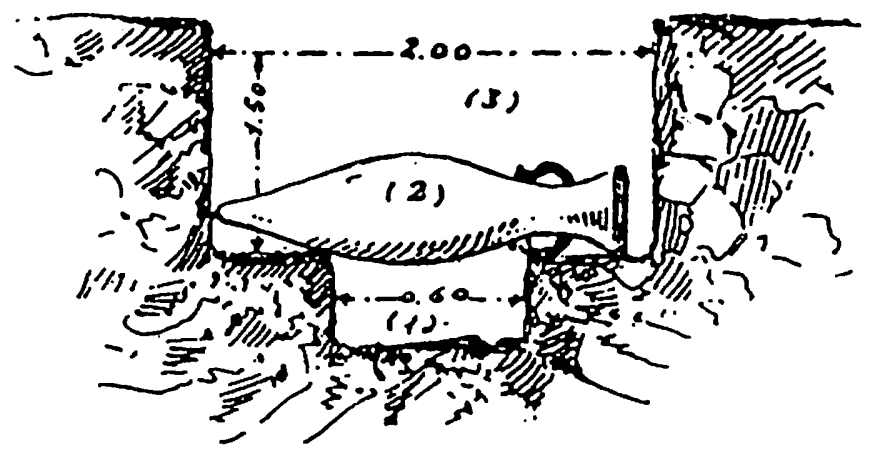

Ficina 2

Corte vertical de una de lats -npulturas: pímicas del cerro de San l.uronzo.

(1) Restos humanos y arena fina.

(2) Juforas de 1.05 a $1.20 \mathrm{~m}$. que cubrian la caja inferior donde.

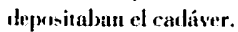

(3) Relleno de pierlra, tierra y Tragumentos is corámica.

toria de este establecimiento fenicio, púnico y romano, que al final de todo, es lo que nos interesa.

Veamos pues lo que de Astarte, de La maga o La abrasadora podemos decir o mantener con los escasos o casi nulos documentos que poseemos en estos momentos y las casi nulas pruebas documentales que anteriores historiadores nos han dejado, por lo que hemos dividido nuestra exposición en los puntos siguientes:

- El posible papel económico de Melilla, situada en la provincia romana de Mauritania Tingitana (2) (Mapa Fenicios en el Mediterráneo) y su conexión con Cartagena, la antigua Carthago Nova púnica, en la Península Ibérica, situada geográficamente frente a frente.

- Importancia religiosa:

1. La presencia en Rusadir (Melilla) de los dioses antiguos y su importancia religiosa y económica, basándome en la presencia de tipos iconográficos de algunas divinidades y sus símbolos en las monedas acuñadas

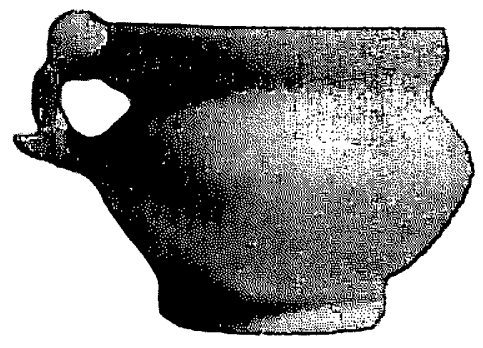

FIC:L:RA 3 Varo ríliew. y encontradas en Melilla, como son espigas, caballo, caduceo y patecos, así como la sal y la inmortalidad, todo ello relacionado con los ritos de enterramiento constatados en Melilla (figura 2), así como los amuletos y el vaso fálico del .Museo de Melilla (figura 3).

2. La diosa Astarté y su culto en el Mediterráneo, en relación con los pendientes encontrados en la necrópolis del Cerro de San Lorenzo y los ritos de enterramiento. 
3. Y finalmente los lugares mágicos o lugares naturales de culto que aún se conservan, islamizados, los Yenún, Baraka, taumaturgia y magia y algunas pruebas que conocemos de estas creencias antiguas.

\author{
EI. POSIBI.E PAPEL ECONOMICO DE MEIILIA. SITUADA EN LA PROVINGIA \\ BOMANA DE MAURITANA TINGITANA Y SL GONEXION CON CARTAGEVA, LA \\ ANTIGUA CARTHAGO NOVA PUNICA. RN IA PENINSLIIA IBERICA. SITIABA

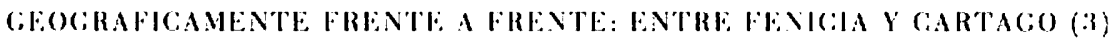

A veces el mar, más que separar, une. A esta conclusión creo que, hace mucho tiempo, llegaron los fenicios, que unieron con sus viajes Oriente y Occidente. Y hace también muchos años que los investigadores hispanos hablamos del Círculo del Estrecho, una realidad histórico-política y económica derivada de la particular configuración de este área geográfica, de la cual forma parte Melilla (4). A esta unidad nos referimos hace algunos años al estudiar los reyes mauritanos y su relación con Hispania, ya que el comercio entre Hispania y el Norte de Africa es evidente desde muy antiguo, según hemos señalado en trabajos anteriores, siguiendo las pruebas aportadas por numerosos autores ( $\tilde{5})$.

Las más antiguas referencias históricas del Mediterráneo occidental han permitido identificar la ciudad de Melilla con la Rusadir citada por Plinio y Estrabón, la Russadeiron de Claudio Ptolomeo o la Rusicada de Pomponio Mela. El Itinerario de Antonino, distingue con el nombre de Promontorium Rusadir a la actual Península de Tres Forcas, llamado Mega Akroterion por Ptolomeo y Akra Megale por Estrabon. Las circunstancias que influyeron en su fundación sería la pertenencia al Círculo del Esrecho. Y desde el principio debió verse incluida tanto en los circuitos económicos como en los religiosos, representados por los templos y el culto de las divinidades fenicio-cartaginesas.

Entre los objetos de este comercio están productos como esparto, plata. salazones y plomo, y no cabe duda que también tendría importancia la púrpura, de la que fueron grandes productores los fenicios, los púnicos y sus herede- 
ros en el Norte de Africa, los gétulos y mauritanos, como señalaba P. Fernández Uriel en el Congreso El Estrecho de Gibraltar (6). Toda esta comunidad comercial estaba, sin duda, organizada o fomentada alrededor del templo de Heracles-Melkart de Gades (7) que tuvo un importante papel económico, desde la época de su fundación, ordenada por un oráculo del dios fenicio Melkart según Estrabon (8) hasta época altoimperial, como fue importante el papel económico de los diversos templos semitas y griegos desde la más remota antigüedad (9), que llegó hasta época romana, sin solución de continuidad, aunque adaptándose a los diversas avatares políticos (10).

Entre los más ilustres templos griegos que se ocupaban de asuntos financieros se encuentra el Artemisión de Efeso (11). Y será precisamente Artemis y las diosas relacionadas con ellas el lazo de unión o el extremo del ovillo por el que comencemos a estudiar el panorama religioso de Rusadir.

En las colonias fenicias, los templos, como señalan muchos autores (12) marcaban el recinto donde los fenicios, nada más desembarcar, habían realizado el primer sacrificio a sus dioses (13), eran también un lugar de asilo para los naufragos (14) y un lugar que garantizaba, protegido por la autoridad del dios, la legalidad de las transacciones (15) además de la existencia en ellos de una función económica principal, recordando que era el Melkart de Tiro el considerado como dios tutelar de las grandes empresas marítimas de esta ciudad, a cuyo templo en la metrópolis se enviaba un porcentaje de las rentas públicas según Diodoro (16), lo que indica que tal vez los templos de algunas divinidades determinadas participaban financieramente en las empresas marítimas, y este porcentaje recibido, el décimo o diezmo, no era solo una ofrenda religiosa basada en la piedad o en el agradecimiento por la protección del dios sino su parte en los beneficios de las empresa marítimas; a las que los dioses (y sus sacerdotes, obviamente) habían aportado varios elementos:

- aporte económico

- información

- asistencia técnica 
Y los santuarios que, como el de Heracles-Melkart en Gades (17), estaban establecidos cerca de los establecimientos comerciales fenicios en el Mediterráneo, tendrían, entre otras misiones, la de servir como parada intermedia entre el templo-banco principal establecido en Tiro y los establecimientos diseminados por el Mediterráneo, (18), uno de los cuales sería el de Gades (19), además de otros posibles diseminados en el Círculo del Estrecho, como Rusadir (20), influencia que se extendió en época temprana a la misma Roma (21).

LA PRESENCIA DE RUSADIR (MELILLA) DE LOS DIOSES ANTICUOS Y SU IMPORTANCIA RELIGIOSA Y FCONOMICA, BASANDOME EV LA PRESENCIA DE TIPOS ICONOGRAFICOS DE ALCLNAS DIVINIDADES Y SLS SIMBOLOS EN LAS MONEDAS ACLÑDAS Y EYCONTRADAS EN MELILLA, COMO SON ESPIGAS, CABALlo, CADUCEO Y PATECOS, ASI COMO LA SAL Y LA INMORTALIDAD, TODO ELLO RELACIONADO CON LOS RITOS DE ENTERRAMIENTO CONSTATADOS EN MELILLA, ASI COMO LOS AMUIETOS Y EL VASO FALICO DEL MUSEO DE MELILLA

Evidencias de cultos antiguos tenemos en los escasos restos arqueológicos que conservamos en Melilla de épocas púnica y romana.

LA IMPORTANCIA DEL COIOR EN LOS ENTERRAMIENTOS

Entre ellos, se citan las necrópolis púnica y romana del Cerro de San Lorenzo, cuyos objetos son la base de los fondos del Museo Municipal, fechada por Juan Cabré en el siglo III a. C. (22).

Sorprende, al leer las noticias sobre esta necrópolis la referencia a una pronunciada decoloración rosácea del terreno en la parte central de las sepulturas, como si sobre ella se hubiesen depositado algunas espuertas de tierra extraídas de distinto estrato, tal vez procedentes de los terrenos que existen en el denominado Cerro de los Camellos (Huerto de las Cañas), como si se tratase de una tierra especial, y el echar esta tierra arcillosa tuviese un significado especial, tal vez la coloración rosácea. En este senti- 
do, cabe referirse a la importancia del color en todo el mundo antiguo y sobre todo del color rojo. Para el hombre antiguo, el color rojo es el color de la sangre y por tanto, de la vida. Entre los sumerio-acadios, este color, samtu, era, sin embargo el color del duelo, el que espantaba a los demonios, comenzando por el espíritu del difunto, que se creía volvía a la tumba y al mundo para molestar a los vivos. Tal vez esta creencia esté en relación con el hecho de pintar los cadáveres de rojo que se aprecia en ciertas culturas antiguas, como la del Egipto Predinástico. Entre los fenicios es sintomático el hecho de pintar de rojo los huevos de avestruz depositados en las tumbas como signo de renacimiento (23). El hecho de cubrir las tumbas con tierra de color rosáceo puede estar relacionado con alguna creencia de este tipo, que por falta de fuentes, naturalmente, solo podemos dejar en conjeturas.

LA IMPORTANCIA DEL, NUMERO TRISS

Se refiere también Fernández de Castro, cuyas noticias, a falta de otras más modernas, seguimos, a que en la necrópolis citada se hallaron ciertos enterramientos especiales cubiertos de ánforas de barro de boca de trompeta, de 1,05 m. a 1,10 m. de altura, colocadas cuidadosamente en sentido horizontal, a falta de losas, sobre los bordes de la fosa sepulcral. Curiosamente, el número de estas ánforas por enterramiento era siempre IMPAR y, como escribe dicho autor, "guardando relación con el tamaño de la sepultura. Así, las tumbas menores estaban cubiertas por TRES ánforas y la mayor de las encontradas por NLEVE".

Una vez más, debemos recurrir a nuestros conocimientos de ciertas costumbres antiguas para poder interpretar, dentro de la mayor cautela, este tipo de rito, que podría estar relacionado con la misma diosa Astarte, como divinidad suprema de la vida y de la muerte, como veremos más abajo. Bástenos decir ahora que para los antiguos, el número en general poseína un valor mágico, místico y oculto. Y vemos en esta forma de enterramiento una intencionalidad, que a falta de mejor explicación podemos relacionar con la creencia que, entre otros, los Pitagóricos expresaban como "la fuerza soberana y autógena que mantiene las fuerzas cósmicas (24). El número tres, sobre todo, tiene para los pueblos del Mediterráneo 
antiguo gran importancia, como expresión del número universal: la relación fundamental del mundo divino en las Triadas de dioses, es el que encierra a la vez la unidad y la dualidad. el más pequeño número par y el más pequeño número impar, el más usado en magia (los encantamientos hay que repetirlos tres veces para que funcionen), el número de la Gran Diosa, Señora de la Vida y de la Muerte, la Gran Madre universal, que se expresa también por el 9; que solo es el 3 al cuadrado.

I.AS CONCHAS

Otra curiosa costumbre que se constata en estas tumbas, que tal vez responda a un rito de resurrección es la presencia de caracoles Helix, puesto que también las conchas, aunque casi siempre marinas, están relacionadas con las divinidades femeninas de la fecundidad y la vida eterna, al participar del simbolismo de la fecundidad propia del agua. Su dibujo y su profundidad de caracola recuerdan el órgano sexual femenino y en la mitología griega la leyenda del nacimiento de Afrodita, la diosa del amor, asimilada a Astarté. Está ligada tanto a la idea de muerte en el sentido de que la prosperidad que simbolizan, para una persona o para una generación, procede de la muerte del ocupante primitivo de la concha, de la muerte de la generación precedente. En el Palcolítico superior (edad del reno), las conchas marinas que figuran entre los aderezos mortuorios simbolizan, para Chevalier y Cheerbrandt, la solidarización del muerto con el principio cosmológico Luna-Agua-Mujer, lo regeneran y lo insertan en lo cósmico: presuponen también, a imagen de las fases de la Luna, el nacimiento, la muerte y el renacimiento (25).

\section{LA ACTTTUD DE BEBIRR, LA L.UZ Y I.OS PERFUMES}

Siguiendo con el especial rito de enterramiento, continua Fernández Castro aludiendo a la presencia al lado de la boca del difunto, casi en contacto con los dientes, de una pequeña jarra de barro, de una lucerna próxima a las vértebras cervicales y unas pequeñas anforitas o ungüentarios fraccionados diseminados a lo largo de la fosa, mientras que en la parte inferior, a la altura de los pies se encontraban tazas o páteras en perfecto estado. 
La posible explicación es, sin duda, muy conocida: Tanto la bebida como la luz son elementos que darán a los difuntos vida en el Más Allá y que están presentes en numerosos ritos de enterramiento, desde la época prehistórica. Unidos a los bálsamos o perfumes, son elementos que contribuyen a remarcan la creencia de estas gentes en la vida eterna, a cuya luz deben conducir la lucerna, mientras que los perfumes o bálsamos se interpretan como ofrenda a las divinidades del Más Allá (26). Tras el análisis, se comprueba que está compuesto de mirra, áloes, bedelio y benjuí entre otros. De entre ellos, la más conocida es la mirra, relacionada con la vida y el Sol, a la que el difunto debe volver, con la resurrección que le proporcionaran los ritos de enterramiento.

En una de las sepulturas púnicas, que según señala Fernandez de Castro, debía pertenecer a una mujer, se hallaron una jarrita, un candil o lucerna, que solían aparecer en estos enterramientos a uno y otro lado de cráneo, dos pendientes de lámina de oro (figura 4), representando cada uno una paloma posada, con artísticos trazos cincelados a mano en su cabeza y alas, unos aretes de oro para la cabellera y varias cuentas de ágata correspondientes a un collar, dos lacrimatorios, dos ungüentarios y fragmentos de un alabastrón troceado que contuvo una sustancia rojiza a juzgar por el tinte que se conserva en su interior.

Estos pendientes, que se conservan, son hoy una de las más bellas piezas guardadas en el Museo Municipal de Melilla.

Y una vez más nos introducen, junto con la importancia del color y la presencia de los demás elementos, en lo más profundo de las creencias de mundo púnico: la diosa Astarté.

It:enst

Pendientes fenicios de

lámina de oro. Cierro de San

Larenzo (Melilla).
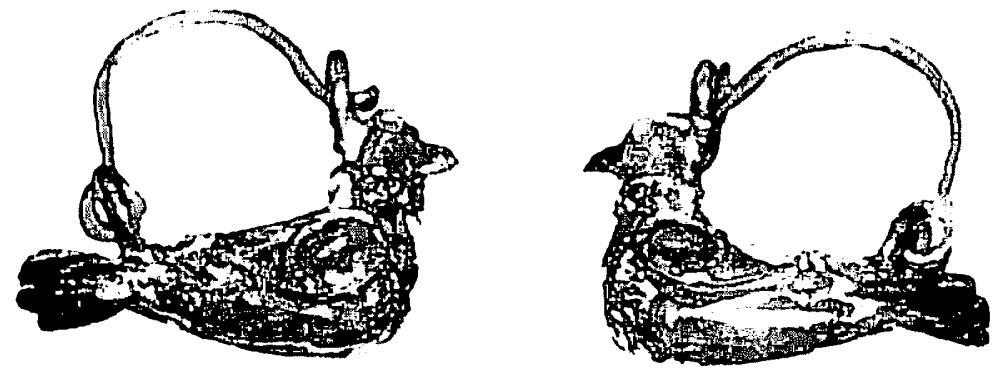
Es curioso y ello muestra la gran importancia de los pequeños hallazgos arqueológicos, como con tan escasos elementos podemos llegar a conclusiones que, si bién siempre entran en el campo de las conjeturas, al menos no están alejadas de lo que se consideran elementos fundamentales de la religión fenicio-púnica.

Verdaderamente no tenemos restos de templos, ni estelas funerarias, ni estatuas de divinidades. Pero este par de pendientes nos permite, de la misma manera que la miel o el raical mel- y el tipo monetal de la cabeza femenina de las monedas púnicas halladas en el puerto de Melilla, en la condición de diosa alada, patrona de la navegación, de la gran diosa de Fenicia, Astarté, que tanta fortuna tuvo en Occidente, hasta ser sustituída por Tanit.

Astarté está unida a los avatares de la colonización fenicia de Occidente y por eso hemos querido que ella diese nombre a esta comunicación (27). Al fin y al cabo, ella sigue siendo la patrona de los marinos, Venus, la Estrella de los Mares, la Virgen del Carmen. La que protege a los hombres de la mar, la que desde su barco, bendice las aguas marinas el día 16 de Julio, a la que los marinos dedican la Salve marinera, como punto final de una figura arquetípica consustancial al hombre: La madre que protege en los peligros. La estella que guía a los navegantes: La que primero se apaga en el cielo. antes que el sol y prepara sus caminos. Y la que primero de ve por la noche.

Esta divinidad femenina ya se cita en los textos de Ebla, en Siria, en la primera mitad el III milenio, aunque se ignora en fechas tan remotas todo lo relativo a su culto y los contornos de su personalidad. Los textos de Emar son más explícitos y se refieren a una multiplicidad de aspectos de esta diosa, caracterizados por epiclesis, posiblemente canónicas, tales como Astarté del combate, de la vuelta, de la mar, de las fuentes, de la destrucción, de la orilla, de la ciudad, de la montaña, del templo mismo del dios de la tormenta, del templo de la encrucijada, etc. que podrían resumirse a tres aspectos principales:

- la guerra y el elemento acuático (fecundidad)

- su caracter poliado de protectora de la ciudad

- y su asociación al dios de la tormenta 
Su situación es análoga a la de la diosa mesopotámica Ishtar, que también poseía múltiples nombres y lugares de culto. La Astarté fenicio-púnica sería el resultado o la síntesis de las diversas manifestaciones anteriores. El examen de la documentación ugarítica parece refozar esta impresión. Allí existían numerosas diosas: Athirat, Anat y Astarté (28), las dos primeras más importantes que la tercera, cuyo perfil es impreciso, sucediendo lo contrario con las dos primeras en el panteón fenicio-púnico, donde sobresale Astarté. Anat resiste bién en Egipto, en asociación estrecha con Astarté; en cuanto a Athirat, pasa por el problema de la ashera bíblica, la esposa de Yahweh (29). Solo resiste en el tiempo Tanit, una suerte de emanación de Astarté o en todo caso una diosa ligada a ella, cuya génesis en el Panteón cartaginés no es muy clara.

Astarté, la diosa siria del Eúfrates Medio, esposa del joven dios Ba'al, diosa guerrera, de los relámpagos y de las montañas, cazadora, diosa de las aguas y las fuentes, que reemplaza a la ugarítica Anat, la Virgen-Madre (30), cuyo culto se difunde por el Mediterráneo es muy diferente en Occidente de la original oriental, debido a que en estas nuevas tierras se inserta en un universo de micro-realidades, que contribuyen a darle características muy diferentes de unos lugares a otros. Se asimila bién a Afrodita, bién a Hera, a Leucotea o a Europa en el mundo griego o Uni en Etruria, signos irrefutables de una personalidad con diferentes facetas, aclaradas solamente por el lugar donde se realiza la inserción. Atenea es una diosa preferentemente del mar y como tal es una diosa protectora de los navegantes, como la vemos en la Odisea, v. 271-275, indicando el rumbo (31) y cobra sentido una Atenea Hippia, íntimamente ligada a la navegación, más aún su templo en Corinto consagrado a una Atenea Chalinitis (32). En la Península hay noticias de un templo de Atenea en la costa malagueña, en la antigua Odiseia (quizá Ulisi) en cita de Asclepiades de Mirlea recogida por Estrabón, m. 4, 3.

En Cartago, Tanit y Ba'al Hammon fueron los dioses del tophet, en cuestiones ligadas a la descendencia y la salud y Tanit suplantó a Astarté en un momento determinado, alrededor del siglo $\mathrm{V}$ a. $\mathrm{C}$.

Los testimonios de Astarté en Biblos y Sidón, en Fenicia, nos la presentan como ụna divinidad dinástica, profundamente enraizada en la realidad 
histórica de los pequeñps reinos fenicios, aunque en Biblos la gran diosa local recibe invariablemente el nombre de Baalat Gubal y no Astarté. Una inscripción giblita bilingüe greco-fenicia del siglo IV a. C. las nombra como equivalentes, aunque para Bonnet, Baalat Gubal estaría impregnada de influencias egipcias y Tanit Celeste sería la hermana joven de Astarté / Juno Regina.

En Biblos, Sidón y Tiro, Astarté es la protectora de los reyes. La que instituye la realeza en Fenicia, ya que ella recibe, según Filón de Biblos, la realeza de manos de Kronos, el dios del tiempo, en compañía de Zeus Demaraos (33). En signo de soberanía, la diosa se presenta con cabeza de toro. Sin duda, la corona hathórica con cuernos no es extraña a esta descripción. Como interlocutora privilegiada del rey; ella es la encargada de interceder por su pueblo. Así, en Sidón, el rey es sacerdote de Astarté.

En el mundo colonial, la diosa se adaptó a nuevas estructuras político-sociales, sobre todo a la desaparición de la realeza. lo mismo que Melkart.

En Oriente se la encontraba como tanto como guerrera como diosa de la fecundidad o en su acepción de divinidad marina. Esta última dimensión es la que prevaleció cuando los fenicios se fijaron, en época helenística sobre todo, en las riberas del Egeo. Así se explica su metamorfosis frecuente en Afrodita Pontia o Euploia, protectora de los marinos. Sus funciones marinas debieron ser enfatizadas por Cartago en relación con las guerras púnicas, pero solo se tiene ecos de ésta actuación insertadas en las noticias de Virgilio que no da un discurso directos sobre los hechos (34).

En cuanto al aspecto de fecundidad-erotismo, se pone en evidencia en Occidente, mientras que en Fenicia está muy poco atestiguado, siendo muy abundante en Ghipre, Sicilia (Eryx), y en Africa del Norte (en Sicca Veneria sobre todo) e incluso en Pyrgi, el puerto etrusco.

Su relación con Tinnit / Tanit tiene otra problemática (35). Se sabe de la transferencia del caracter de poliada o tutelar de todos los grandes centros fenicios de Astarté a Tinit, representada con los rasgos de una Tyché en las monedas, sobre todo en Cartago, donde es el genio, daimon, de la ciudad. 
Otro rasgo curioso de esta diosa y un distinto con respecto a Astarté es que Tanit es rara en la onomástica púnica, mientras que Astarté es muy abundante, tal vez como rasgo conservador y arcaizante (36).

En cuanto a la interpretatio clasica de la diosa, Filón de Biblos llama a sus hijas las Artémides. Esta identificación con Artemis no es muy frecuente pero se explica por dos consideraciones: Por un lado, para Filón, Artemis es la "hija virgen del dios Urano", por otro lado, la relación de Astarté con la caza sobre todo en Lgarit y Emar en el II milenio, aunque no en el mundo fenicio-púnico. Tal vez lo primero sea el origen de la identificación Artemis=Tanit, llamada a menudo en el Africa romanizada Virgo Caelestis, que una inscripción bilingüe de Atenas nos confirma, ya que Abdtanit se traduce por Artemidoro (CIS I 116 (= KAI 53). El mismo Filón de Biblos (l 10,31) hace hijo de Astarté a Pothos, el Deseo, y Eros, el Amor, lo que indica una identificación a Afrodita, que el autor reafirma explicitamente más adelante, diciendo "Astarté dicen los fenicios, es Afrodita".

Algunos autores hacen la asimilación siguiente:

\section{Oriente: $\quad$ Astarté $=$ Afrodita $/$ Venus \\ Occidente: Astarté = Hera $/$ Juno}

pero la situación es más compleja, pues la asimilación Astarté-Afrodita se basa en el caracter erótico, entendido como pasión irresistible, elemento bién patente también en la diosa egipcia Hahtor, asimilada, como Isis, a Astarté y también como rasgo ligado a la procreación,

Astarté y Afrodita tienen también connotaciones celestes (Afrodita es Urania cuando equivale a Astarté) y marinos (Afrodita nace de la espuma del mar). Esta asimilación está atestiguada en Oriente, también en Chipre y la importancia atribuida modernamente a esta asimilación se debe, según Bonnet, a que Astarté está implicada en el proceso de formación de la Afrodita griega, lo que Herodoto y Pausanias señalan (37).

En Kition, Paphos y Amathonte, Astarté y Afrodita se confundieron en un mismo culto. $Y$ hay que anotar, asimismo, que en época helenística, con los comerciantes orientales establecidos en Delos, Cos, en el Pireo y en 
Tesalia, Astarté se introdujo en Grecia como Afrodita, pero con el aspecto particular de diosa marina, llamada Euploia o Pontia, protectora de los marinos.

Además de esto, en Oriente, diversas fuentes atestiguan esta asimilación. Aquiles Tacio y Luciano nos describen a Astarté con los rasgos de la princesa Europa y le atribuyen un caracter lunar.

Una inscripción griega tardía de Tiro coloca al lado de Heracles-Melkart una cierta Leukotea, que corresponde a Astarté aquí, como antes en Oriente y en Pyrgi. Ahora bién, Leukotea es un personaje mítico ligado a la mar, protectora de los marinos, así como una figura maternal, en su cualidad de nodriza de Dioniso niño. También es una diosa oracular, lo que podría relacionarla ulteriormente con Astarté. que profetiza en diferentes lugares de culto. En Deir el-Qala, en un lugar alto de la ciudad de Beirut, la paredra de Baal Marqod es probablemente Astarté, que las inscripciones denominan Hera o Juno regina, aquí diosa oracular.

En Occidente, la situación no es uniforme. La asimilación es con Hera / Juno tal vez porque en el panteón romano, Juno es mucho más importante que Venus. En Tas Silg, en Malta, Astarté es claramente Hera / Juno, pero en Pyrgi, las fuentes clásicas reconocen en la Astarté-Lini de la famosa inscripción fenicio-púnica bien a Hera / Juno bien a Leukotea o a Eileithiya, la diosa griega que protege los nacimientos. En Sicilia, en Eryx, en el famoso santuario en que se practicaba la prostitución sagrada, Astarté es Venus y esta Venus Ericina fue introducida oficialmente en Roma en 217 a. C. en plena $2^{\mathrm{a}}$ guerra púnica.

Además de la interpretación clásica, se debe tener en cuenta las diferencias locales y el eventual sustrato indígena que en el caso de Tas Silg y Erix hunde sus raices en cultos prehistóricos, con su figura de Gran Madre.

La asimilación a Hahtor e Isis parece corresponder a dos fases distintas, según ha demostrado Gabriella Scandone Matthiae (38), siguiendo el progresivo ascendente e importancia que Isis adquiere sobre Hathor en el mismo Egipto.

El problema de la iconografía de Astarté es también muy delicado, por lo dificil de interpretar el lenguaje de los símbolos y de hacer hablar a las 
imágenes. Una iconografía canónica de Astarte la presenta entronizada, sentada sobre un trono flanqueada de leones o esfinges, tal como aparece en Motya o Solonte. Otras veces aparece el trono solo o conteniendo un betilo o una "urna de vida", como en Cartago, Tiro o Umm el-Amed. Entre sus atributos figuran los leones, sobre los que aparece desnuda. como en Samos, la paloma, las aves y los elementos vegetales. La presencia de un aerolito en las monedas de Tiro señala su ecepción urania, así como el creciente o las estrellas que se le asocian a menudo.

Tanit, como Astarté, es representada como curotrofa, así como con rasgos leoninos y como Astarté, tiene las aves como emblemas.

España ha dado la única representación segura de Astarté en Occidente, ya que así lo dice la inscripción de la Astarté de Sevilla (). Las letras $h r$ de dicha inscripcón pueden hacer referencia a una gruta, que según Avieno, acogía un oráculo de la diosa, como en Wasta, en Tiro, aunque también puede tratarse de una Astarté funeraria, siendo $h r$ el tèrmino usado para tumba o la Astarté hurrita que aparece en los textos de Ugarit, ya que la inscripción es arcaica.

En Gades, Astarté es adorada junto con Melkart, como en todo medio tirio, metropolitano o colonial, de la misma forma que se adora a Eshmun, el Baal de Sidón en medios coloniales sidonios y a Adonis en Biblos. También en España, los autores clásicos dudan en denominar a un cabo de Juno o de Venus (Pomponio Mela II, 96; Plinio. NH, III, 7: Ptolomeo II, 4, 5; Avieno, OM 437-438), posiblemente, en sus orígenes, el cabo de la divinidad marina indígena identificada con la diosa semita, más tarde romanizada.

\section{LAS AVES Y LA NAVEGACION}

En cuanto a la relación de las aves y concretamente la paloma con Astarté se debe, sobre todo, además de las connotaciones eróticas del animal, a la utilización de diferentes aves como ayuda para la navegación, teniendo en cuenta que esta diosa es la que protegía las navegaciones.

La navegación de altura requiere forzosamente el conocimiento de medios de orientación (39). El más elemental debió ser la posición y trayectoria del sol durante el día y por la noche la orientación por las estrellas. 
Sin embargo, la documentación más antigua, tanto arqueológica como literaria sobre la orientación en el mar hace referencia a la que se basa en el seguimiento del vuelo de las aves. Hace unos años fue retomado el asunto por J. Ma Luzón, siguiendo la hipótesis ya planteada por Hornell (40).

La navegación nocturna durante varias jornadas en altamar, sobre todo cuando se trata de travesías sin visión de costa, necesita algunos conocimientos de astronomía. Estos son evidentes en los textos homéricos, en los que se hace referencia a las Pléyades y las Hiadas de la constelación de Tauro. la Osa Mayor (Arctus) y la Menor y por ello la orientación a partir de la Estrella Polar:

“... las estrellas que el cielo coronan, las Pléyades, las Hiádas, el robusto Orión y la Osa, llamada por sobrenombre el Carro, la cual gira siempre en el mismo sitio, mira a Orión y es la única que deja de bañarse en el Océano..." (II. XVIII, 483-489).

La Estrella Polar era conocida entre los griegos como phoeniké, lo que parece poner de manifiesto que los fenicios desarrollaron con anterioridad a los griegos una orientación astronómica, tal vez con conocimientos adquiridos en sus contactos con los egipcios del III milenio, y, desde luego, de Mesopotamia. Los propios griegos atribuían la innovación de la orientación astronómica a los fenicios (41).

También algunas diosas fenicias que asumen el papel de protectoras de los marinos, como Astarté-Tanit, se las representa a veces con las alas plegadas sobre el cuerpo, como recuerda $\mathrm{M}^{\text {a }}$ Augenia Aubet para Ibiza, en el santuario de Es Cuieram (42) o con una paloma como atributo en sus manos (43), lo que podría ser un recuerdo mitificado, similar al que hemos expuesto para el mundo griego, de la orientación mediante el vuelo de las aves.

Sobre esta diosa, recuerda Avieno (O. M. 158-160) que en Hispania existe el cabo de Venus, que era la versión romana de la Astarté fenicia o Tanit desde el s. V a. G., a su vez identificada con Iuno Dea Caelestis en la época romana, que tuvo un templo en la colonia romana de Ilci Augusta (44). 

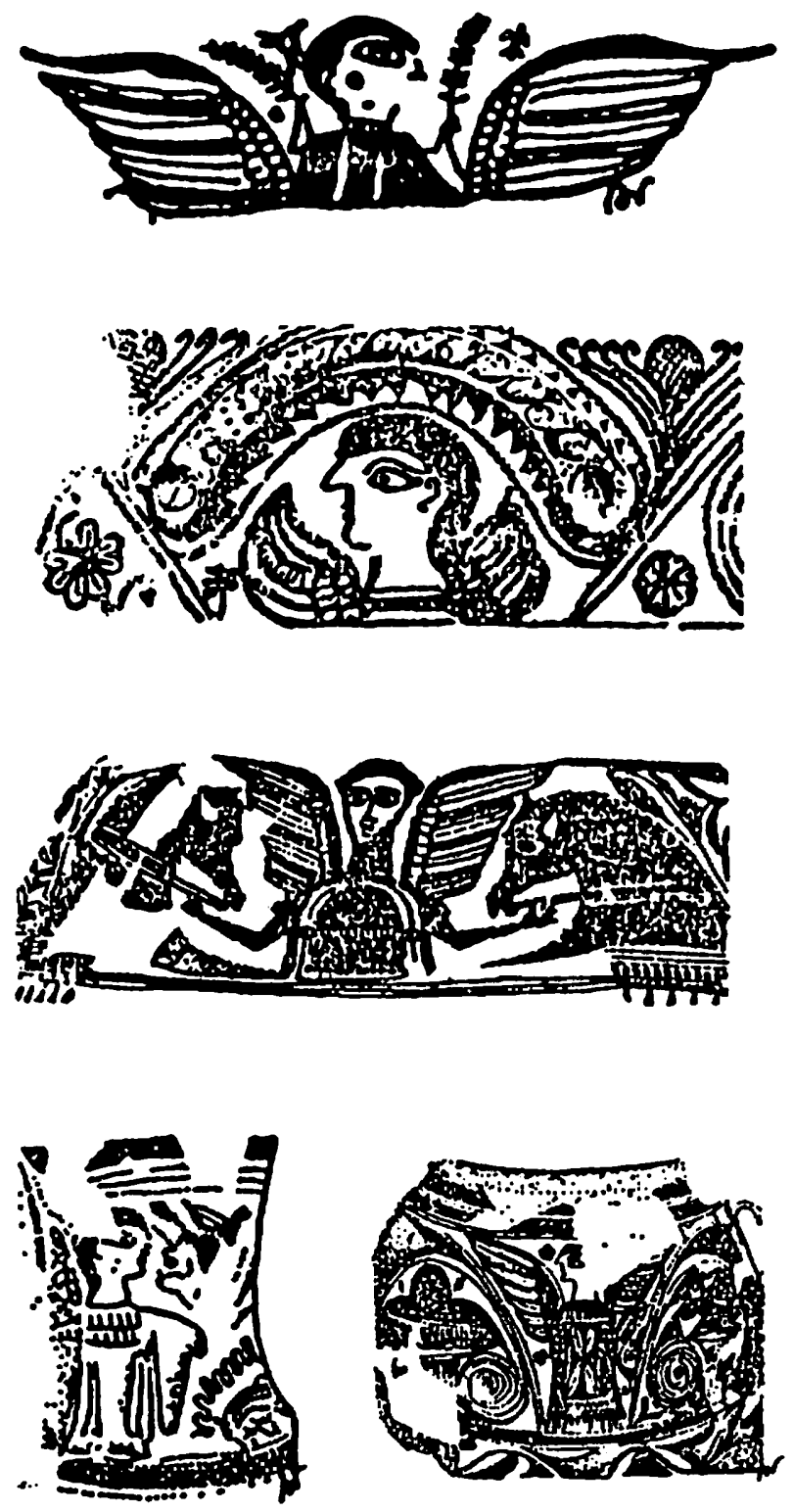

Figina :

Representaciomes de $A$-larte alada sobre la cerámica de Fiche (Colerrion Ratmos liolupies). 
Cerca de Gades, en la isla de San Sebastian, había otra isla consagrada a Astarté (45). Consagrados a la diosa Tanit estaban el cabo de Trafalgar y toda el área ibérica de influencia púnica está jalonada de islas, promontarios, templos y santua-

FIGUHA

Anversio y reverso de momerlas cartaginesas, perteneciente- al lesoro cmonirado en el purrio de Melilla en 1981 rios erigidos en honor de la diosa Astarté-Tanit, en realidad existían una serie de cabo e islas consagrados a la Venus Marina o Noctiluca, según Blázquez una interpretatio romana de la diosa fenicia Astarté (46). Festo Avieno nos informa de estos lugares santos, nombrando el Cabo Higuer, el de Trafalgar (47), el de Gata, el de Baria, la isla de la Luna, frente a Málaga, o la isla de San Sebastian, en Cádiz (48), donde Astarté tuvo una gruta con oráculo y un templo (49).

En el periodo turdetano e ibero. las diosas semitas Tanit-Astarté son asimiladas por los indígenas a su diosa de la fecundidad y en la época romano-republicana prosiguen los cultos bajo las formas de diosa alada y las denominadas Damas, como las de Baza, Cerro de los Santos, Guardamar o Elche, que otras veces aparece como Señora de los animales, de los caballos o de las serpientes (50), que encontramos, por ejemplo, en las cerámicas de Elche, de forma muy parecida a como aparece por todo el Mediterráneo (figura 5). Ella es la gran diosa de Cartago, que
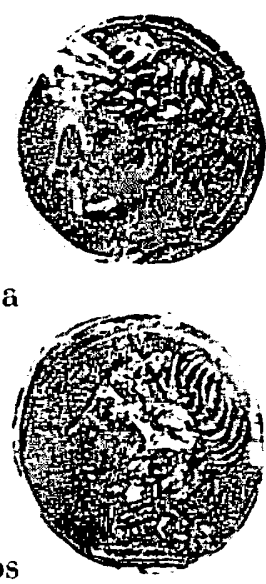
aparece en las monedas púnicas (figura 6) y cuyos símbolos figuran en las monedas hispanas. Así, el caduceo acompaña indistintamente a Tanit, Melkart y Ba‘al Hammón. Para $\mathrm{M}^{\mathrm{a}}$ P. García y Bellido (51), en las monedas de Asido está representada la triada máxima de Cartago: Ba'al Hammon simbolizado por el toro, Tanit por el caduceo y astros y Melkart por el delfín. Sin embargo, esta autora se inclina a pensar que los reversos de Asido aluden a la diosa cartaginesa Tanit y que el delfín, los sábalos con creciente unido a la espiga entre caduceos, en Ilipa, representan a la diosa, que en esta última ciudad, la efigie de Tanit sigue la moda africana. En el reverso de los semises de Asido aparece la espiga de Astarté-Tanit frugífera. Símbolos de la diosa son las monedas con letrero latino, con caballos en el anverso y atún y creciente en reverso. 
En Turdetania, Tanit gozó de gran aceptación, como lo prueban las dedicatorias a Dea Caelestis, a Diana y a Minerva. En los ases de Turirecina se menciona la Virtus de Tanit y su caracter de Victrix e Invitrix. Piensa esta autora que los soldados africanos llegados a Turdetania durante la Segunda guerra púnica inyectaron nueva fuerza al culto a esta divinidad. Tanit y posiblemente Eshmun están representados en las monedas más antiguas de Cástulo, ciudad muy unida a los Bárquidas. Para $\mathrm{M}^{\mathrm{u}}$ Paz Garcia y Bellido, Astarté-Tanit debió ser una divinidad muy adorada en Cádiz, siendo Melkart su paredro. El culto romano de Minerva en Cádiz sería, para esta autora, consecuencia del de una Astarté guerrera local.

ASTARTE, MLLLILLA Y LA MIEL.

Finalizaremos con otra cuestión que también se ha barajado a menudo, como es la raíz mel- que lleva el nombre de Melilla.

En un artículo de Claudio A. Barrio sobre la protohistoria melillense (52), aludiendo a las citadas fuentes numismáticas, en concreto a la moneda fenicia con la leyenda RLSSADIR del Gabinete Real de Numismática de Copenhague, que tiene en el reverso el tipo de la abeja y unas espigas (figura 7), símbolos que coinciden con los de otras ciudades del Mediterráneo sometidas a la influencia griega (figura 8), se refiere a otras monedas con la leyenda Melyta, así como a otas monedas, de Museo de Tetuan y del Instituto Valencia de D. Juan con el mismo símbolo, acabando por confirmar que la abeja es el símbolo numismático de la Protohistoria melillense.

Otro hecho es el hallazgo de miles de monedas en los dragados del puerto de Melilla, de los que el último data de 1981. Dichas monedas son de los siglos III-II a. C. y sobre cllas aventura las siguientes conclusiones:

1. Respecto a las escasas monedas (unas doce) de plata de electron (medios siclos), sículo-púnicas, es decir, cartagineses de los años 260-240 a. C., tienen en el anverso la cabeza de Persephone-Tanit, de nítido perfil griego con corona de espigas y en el reverso el caballo parado. símbolo de Cartago. 


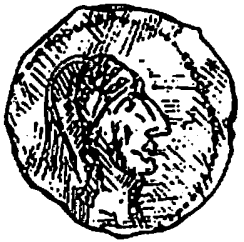

Anverso: Cabivo con gorro ronione infulas encout rado on Lixus dol sigho I

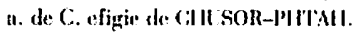

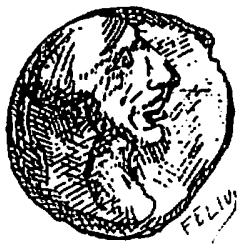

Anvers: cabeza de (iabiro de Lixus (I.uracle) muy men y expresiva.

Dos monerdas

1. fonicia: siglo I a. d. (:.

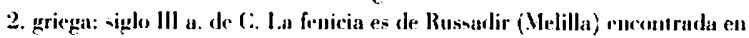

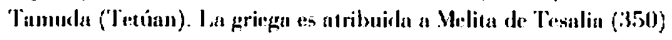

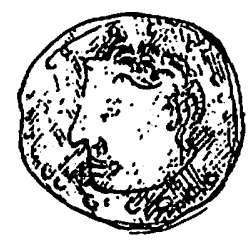

Anverso: rubran de llerrule-"? dentru de arafilu.

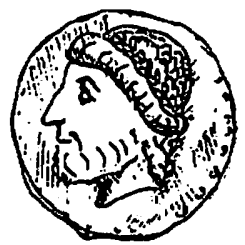

Anverso: cabeza de llercule iorommala ite laurel.

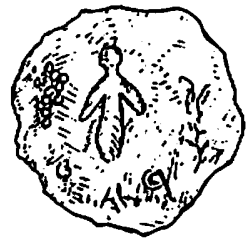

Roverso: atreju, fanmpuada de espigas s

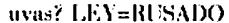

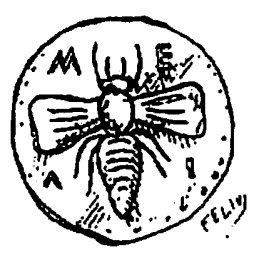

Meveroe: abeja. flanguesuda de buena factura: 1.FI, MIl:I,TA. 
FIC:TISA H

I. N 1.118: Tarra, en Grola.

Cabeza de cabra/abeja.

2. N" I.484: Ffeso, en Jonia. 387-295 a. C. Ciervo y

pulsmera/abeja.

3. N" I.686, de Melitus, en T'esalia,

351) n. de C. Cabera de: \%ens/Abejn. AF $1+15$.

+. $N^{\circ} 1.087$, de Julis, rn la isla egea de Cens. S. III a. C. Calueza de Zeus (o Aristeoly/Abeja.

5. $\mathrm{X}^{*} 1.688$ de Julis, en ln ista cgen te Cors. S. III a. C: Caheza de Apolo (o Aristeo)/Alseja. AF 11.

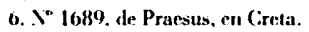
300-200 a. C. Cabeza de

Persefone/Abeja. Hetuidrnema. 40 gin. AK 13.

7. N"1.690, de Elyrus, Iambien en Crea. 400 - 300 a. C. Calbezu de cabra y lanza/Abeja. 78 guı (Dracima). AH 21.

8. $N^{*} 1.691$, de Lisus, Inmbiñu en Cireta. $400-300$ a. C. Alseju/caleza de calora.

9. N" 1.692, de Efero, en Jonin. 280-258 a. c. Ciervo/Abeja. 10. $N^{*} 1.6193$, de Arados, $(n$ Fenituin, 174-118 a. C. Ciervo delunic de palmera/Abeja (coppiado de un lipo de Efeso). b.3 gan

(Arucma). AR 17-18.

11. N" 1.694. de Esmirnu, en Jonia. Epoca imperial romana

Delfin/Abrja.

12. No 2.706 de la isla epen de Cenos. S. Ill a. C. Fstrella de ocho pumis/ Atseja.

Sg. I'lam, R., Greek cuins types end thrir identification. Edl. Sunley, I condros. 1079.

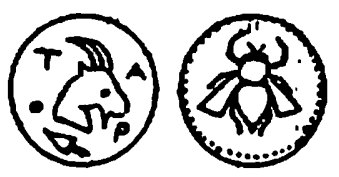

1

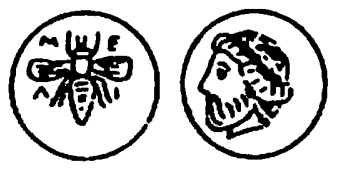

3

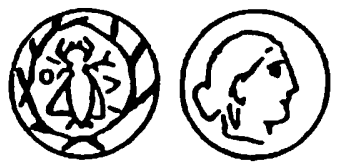

5
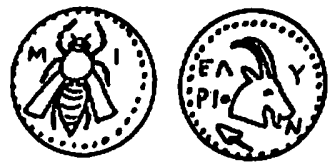

7
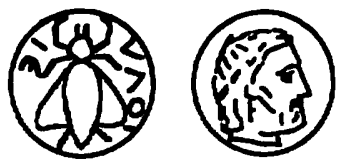

4
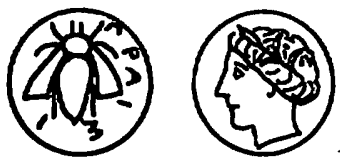

6
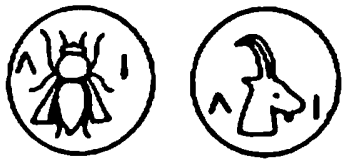

8

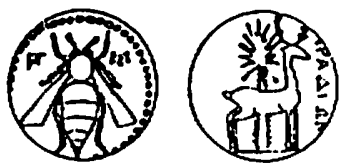

10
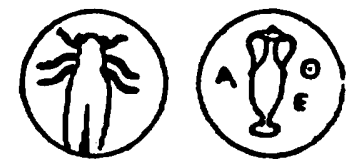

13

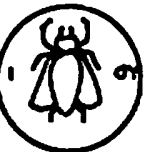


2. El mayor hallazgo de monedas (varios millares) corresponde a las de estilo cartaginés-africano en bronce y cobre, en las que figura en el anverso Persephone-Tanit con dos espigas de trigo y una soga en el peinado y con un colgante y collar formado por pequeños colgantes, en cuyo reverso figura un caballo parado a la derecha retrospicente, con grafila punteada que casi parece lineal, sin atributos o con ellos, consistentes en caduceos, palmeras, plantas etc., amén de distintas áreas fenicias, cuya cronología puede situarse en el siglo III, en época Barquida. Y son, para Villaronga el único documento de la época del 237-206, correspondiente a la preparación, desarrollo y desenlace de la Segunda Guerra Púnica.

Con respecto a las acuñadas en la Península en la misma época, señala Barrios la constante de una serie de variantes:

1. Siempre se trata del tipo de la cabeza de divinidad femenina, mientras que en la Península aparece también el tipo de Melkart

2. Coinciden las símbolos, apareciendo tanto la estrella de ocho puntas o disco solar como la palmera.

3. En las encontradas en Melilla aparece el caduceo reemplazando en su función a la palmera $y$, sobre todo, un pequeño brote de palmera (a veces semeja una flor de lis) que emerge de la grupa del caballo y corresponde con la actitud retrospicente de este que, o bien la venera o hace además de comérsela, simbología que, según el autor citado, no aparece nunca en los hallazgos peninsulares.

\section{LA MIEI.}

No podríamos terminar nuestra ya larga exposición sin hacer referencia a la miel, y a la problemática de su relación con una divinidad fenemina, que a veces puede relacionarse con Astarté-Taniy y otras veces se relaciona con el culto de Saturno.

La descripción, en poética frase del entomólogo americano Wheeler, de la abeja como animal divino "voluntariamente escapado del jardín del 
Eden para endulzar el destino del hombre expulsado del Paraíso", tal vez sea la mejor manera de definir nuestro pensamiento y las líneas generales por las que discurrirá este trabajo sobre la miel, uno de los alimentos más nutritivos que la sabia naturaleza ha proporcionado al hombre y su productora, la abeja. Bién sabemos que, según el más extendido concepto de nuestra civilización, el alimento físico nutre al cuerpo material. Pero también es cierto que el hombre está compuesto de cuerpo y alma. Y por eso, no solo necesita nutrir su parte física con alimentos físicos, sino que, además, debe alimentar su alma, su parte psíquica, con alimentos espirituales.

Tal vez sea esta una visión demasiado simplista de algo tan complejo com es el ser humano. Pero, reducida a su expresión más sencilla, esta afirmación puede llegar a explicar por qué, en un momento determinado, la miel pasó, de ser un alimento humano, a convertirse en una substancia divina, manjar de los dioses que, cuando se daba a los hombres, los acercaba a la divinidad. $Y$, sobre todo teniendo en cuenta que el hombre antiguo, al igual que, en otra dimensión histórica, lo hace el hombre actual (tan parecido y semejante a aquel), llenó su necesidad espiritual con mitos, relatos, cuentos, fantasías, recuerdos y deseos, pero también con realidades. $\mathrm{O}$, tal vez podamos decir que, a veces, el fundamento de estos mitos o fantasías fueron esas realidades cotidianas a las que elevó a la categoría de mitos, a menudo relacionados con las divinidades (53). Para los griegos, mythos significaba simplemente "relato" o "lo que se ha dicho", en una amplia gama de sentidos que iban desde una pequeña expresión oral al del argumento total de una obra literaria. Para Platón, el primer autor griego que emplea el término mithologia, esta palabra no significa más que contar historias. Aunque no nos extenderemos aquí en las diversas teorías sobre el origen de los mitos, muy bién estudiados, entre otros autores, por G. S. Kirk (54) sí examinaremos, brevemente, dadas las características de este trabajo, cómo, en nuestra opinión, y en la de los autores antiguos y modernos que consultamos, un alimento tan básico para el hombre en la Antigüedad como la miel, pudo llegar a ser considerada como el "manjar de los dioses". 
CARACTERISTICAS ZOOL.OCHCAS DE L.A ABEJA

La abeja, (Apis mellifera), es un insecto himenóptero provisto de dos pares de alas membranosas unidas y de un aguijón venenoso. Presenta una organización social muy elevada, y se diferencia en castas, especializadas en las actividades que realizan en la colmena (55).

Pero decir "abejas" resulta muy poco significativo, cómo lo sería hablar de pájaros o mamíferos, ya que en el mundo existen en la actualidad unas 20.000 especies de abejas y no todas se ajustan al complicado y complejo modelo de sociabilidad de la abeja común o melífera (Apis mellifera), que, de origen africano según los naturalistas, ha sido introducida por el hombre en todo el mundo.

La Abeja melífera, es, posiblemente, el insecto más estudiado del mundo, sobre el que se dispone de mayor información. Y esto no solo por su utilidad directa, sino también porque, a lo largo de milenios, la perfección de sus sociedades ha fascinado a los hombres de espíritu inquieto $y$ mente inquisitiva. $Y$ también porque la miel, conocida ya como alimento físico excelente desde la Prehistoria (56) se convirtió, debido a las extraordinarias propiedades que el

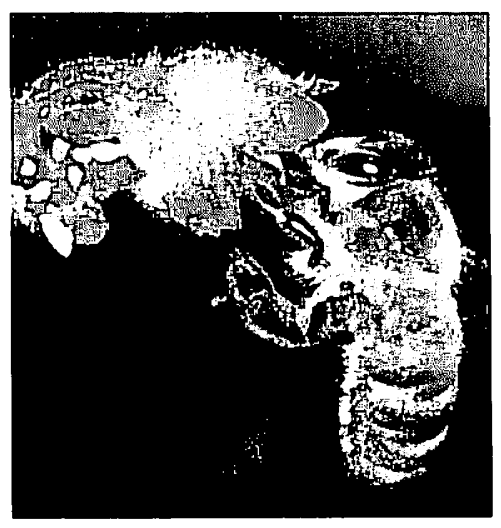

FII:Lin,

Alecja libando umu fler. hombre veía en su productora y en la substancia que elaboraba, en un alimento espiritual, en una comida "de inmortalidad", que justifica plenamente la poética frase de Wheeler con la que hemos comenzado este trabajo.

I.A ABEJA Y B. HOMBIE. SU DOMFSTICACION

Sabemos que desde los tiempos más remotos, el hombre buscó en la naturaleza el alimento indispensable para su mantenimiento y entre otros, debió conocer desde época muy remota, por casualidad, como tantas casualidades, (que podemos suponer, en unas cosas y que sabemos con certeza de otras) las abejas salvajes, de las que supo aprovechar, básicamente, la cera y la miel (figura 9). 


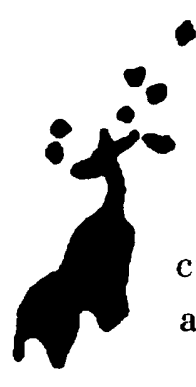

a

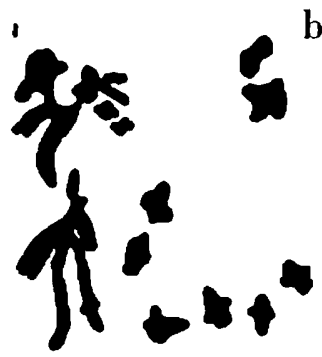

b

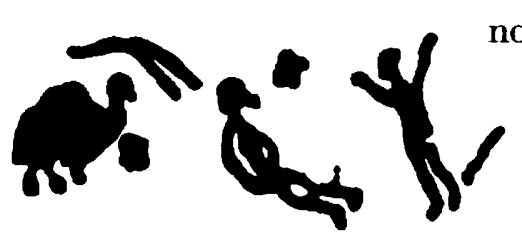

$c$

FIC:TRA to

Abejiss asociadris a figares animales o huminus.

a) I a Vacada

b) Mas de Ramón dien Berso v) Polourin

Sg. Mams. Lyu R.: "Alseilles et recolte du micl dans l'urt nupestre du Levant espagnol". Homenaje a Almagro. 1. Madrid, Ministerio de Cultura. 198:3, pp. 36; $3-36$, fig. $2.1 n$

Es natural que el trabajo preciso de la abeja, su laboriosidad y su curiosa organización social llamase la atención del hombre primitivo, convirtiéndose en una especie de "animal doméstico" cuando aprendió a fabricarle colmenas artificiales, siendo muy abundante su representación, aún en estado salvaje, en cuevas del Levante español (figuras 10 y 11).

La importancia que tenía la miel en la alimentación de los hombres en la Antigüedad, substituyendo al actual azucar, era enorme (57). La miel, en acadio dispu se utilizaba ya en Babilonia, aunque la que se cita en los textos suele ser jarabe de dátiles. Donde ya debió tener mucha importancia fue en Asia Menor. Allí en el siglo VIII a. Cr., un gobernador, Shamash-reshu-ussur, en el Eúfrates Medio, se jacta de haber introducido la cria de abejas (58) y a veces la encontramos equiparada al vino y al aceite o a la leche, aliméntos básicos de la Humanidad junto con los cereales. Pero no solo los productos de la abeja tuvieron una enorme importancia sino que pronto el animal que los producía dejó constancia en la Historia de su valor para los hombres por su posición en los mitos relacionados con las distintas clases sociales.

Y así, sabemos que la abeja también ha sido considerada durante toda la Antigïedad como un símbolo de realeza, desde Sumer, cuya escritura asociaba su imagen a la idea de "rey", hasta la época imperial romana, en la que emjambres de abejas cubrían la estatua de Antonino Pío anunciando su elevación al trono (59).

Símbolo de abundancia y prosperidad, la miel, como recoge un versículo del Antiguo Testamento:

"He bajado para librarle de la mano de los egipcios y subirle a esta tierra que mana leche y miel" (Exodo n 3. 89). 


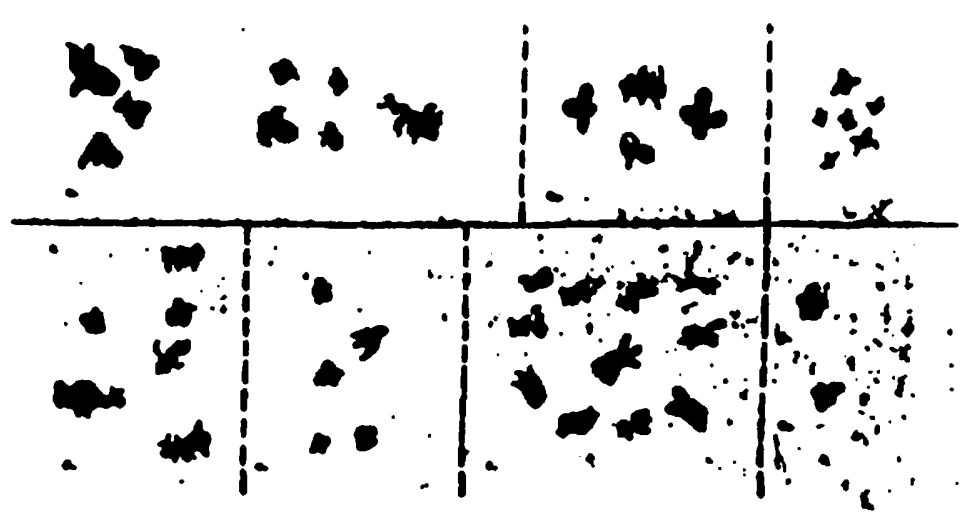

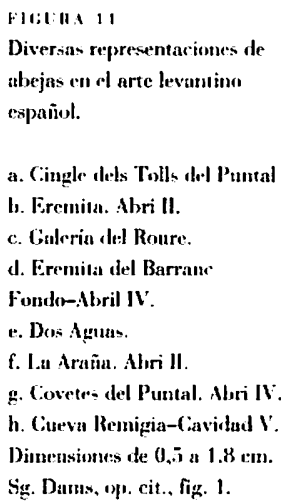

era también alimento altamente nutritivo con el que solía alimentarse a los niños:

"in Graecia infantes primum melle alebantur, quod ex Paulo et Aetio monstrat Is. Vossius ad Bernabe Epist. p. 311: cui rei ollulam cum spongia adhiberunt" $(60)$,

costumbre que aún sobrevive en algunas partes del mundo griego. Así, en Rodas, donde aún ahora, al niño, ocho días después de su nacimiento se le coloca por primera vez en una cuna donde otro niño toca sus labios con miel, deseándole que toda su vida sea tan dulce como ella.

Esta importancia de la miel en la alimentación de los niños se refleja sobre todo en la mitología griega y romana, en diversos ejemplos casi siempre relacionados con el alimento de los dioses. Así, fue el alimento, recogido en la gruta sagrada del Ida, en Creta, con el que Melissa crió a Zeus. En esta isla, Zeus Cretagenes está intimamente relacionado con la abeja, animal que aparece a veces en las monedas emitidas por ciudades de la isla (figura $\left.8, n^{n \leqslant} 1,6,7,8\right)(61)$ y sirvió de alimento del niño Attis, abandonado por su madre, además de la leche de cabra (62). También Dionysos fue alimentado con miel, en la isla de Eubea, por Macris, hija de Aristeo (63). 


\section{MIISI. Y MEDICINA}

Ĺtilizada en medicina, concedida a los hombres, según Ovidio, por la ninfa Cloris (o Flora) (64), la miel era y sigue siendo actualmente utilizada en Medicina por sus poderosas cualidades antisépticas, ya que no deja desarrollarse en ella ningún organismo, por grande o pequeño que sea, de aquí que fuese un extraordinario conservante de frutos y también de aquí, su relación con la inmortalidad, puesto que mantenía "como en el momento en que fueron depositados en ella", los productos que en ella se introducían, sin permitir su putrefacción. Por eso se utilizaba para embalsamar y conservar los restos orgánicos, detalle que recuerda Plinio (65) al referirse al hecho de que la piel de la salamandra era utilizada como antídoto contra las quemaduras y se decía que ciertas partes del animal conservadas en miel abrían el apetito sexual (66). Este mismo autor refiere que se tenía tanta confianza en este producto porque se decía que había sido inventado por el sol, o que procede directamente de él (67).

Sus propiedades como conservante la hace ser utilizada en los rituales funerarios. Así, sabemos que en la antigua Grecia se embalsamaban en miel los cadáveres de los niños o de aquellas personas a las que no se quería incinerar directamente, (68) y que, desde luego, debían tener un gran poder económico, dada la consideración de la miel como producto de lujo. A este respecto debemos recordar que Glauco, ahogado en miel, de cuya muerte y resurrección hablaremos más abajo, era hijo del rey de Creta.

El origen de esta práctica de conservación de cadáveres en miel parece de origen oriental. Y tal vez, como podemos suponer por el mencionado mito de Glauco, se transmitiese, ya antes del II milenio a Grecia a través de Creta, isla de estrechos contactos comerciales con el área del Mediterráneo oriental (69), existiendo pruebas del mantenimiento de estos rituales aún en época histórica. Tal vez el caso de Alejandro Magno, embalsamado en miel sea el más famoso (70).

De su importancia en medicina sabemos que se utilizaba también junto con diversos órganos animales para tratar la epilepsia. Y Alejandro de Tralles menciona un remedio para tratar esta enfermedad compuesto de orina de jabalí, secada al humo, diluída en vinagre y miel (71). También por 
medio de la miel se favorecía la dentición de los niños, según Plinio, mezclándola con dientes de delfín (72), mientras que los vómitos de sangre se curaban en el santuario de Asclepio, en Lebena, con una mezcla de miel hecha con piñones de las piñas utilizadas para calentar el altar del dios (73).

\section{I.A MIEL Y I.I MACIA}

De estas y las anteriormente citadas cualidades de la miel deriva también su consideración como una sustancia mágica. Así. leemos en un encantamiento:

"Toma conjuntamente dos de tus uñas y todos los cabellos de tu cabeza y deifica un halcón en leche de una vaca negra mezclada con miel ática" $(74)$.

Aquí se entiende por "deificar" como "ahogar en un líquido" para liberar el pneûma o espíritu del animal, que luego asumirá el mago al beber la leche y la miel (75), hecho que el mismo texto mágico resume en la frase siguiente:

"Torna la leche con miel, bébetela antes de que salga el sol y habrá algo divino en tu corazón".

Vemos pués a la miel como elemento divino, proporcionando al hombre alguna de las cualidades de la divinidad con la que tiene conexión.

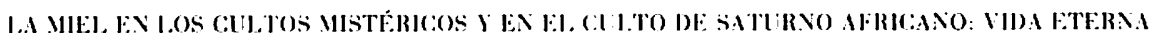

Aunque, como ya dijimos, la miel es un producto muy importante en el comercio de la Antigïedad (76) rara vez se han encontrado recipientes conteniéndola, tal vez porque hasta ahora se ha desconocido su importancia como producto de lujo y también religioso que debió ser objeto de un activo y lucrativo comercio. Hasta hoy, aunque se intuye que debió depositarse en las tumbas como ofrenda a las divinidades del más allá, solamente conocemos con certeza que la contenían algunos pocos vasos, encontrados en tumbas, como los recipientes de bronce, hallados en una tumba de Paestum 


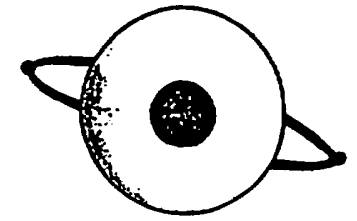

Sg. Burms. L.. up. cit.. litu. 25. 2.

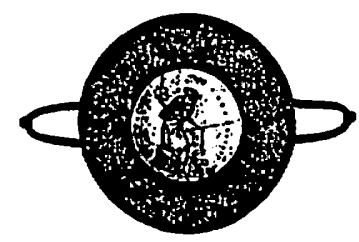

Sig. Bunss. L... op. cit... laim. 26. I
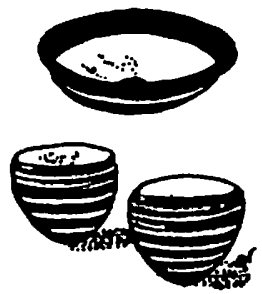

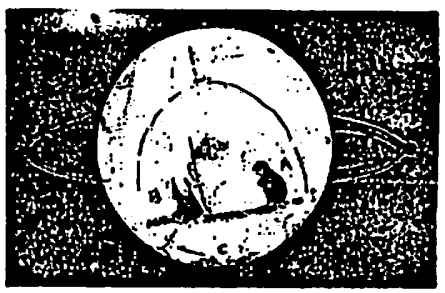

Copm I" I. Sg. Burns, up. cì., lám. $A, 1$ y 23, 1.

a. (iluturos.

b. Poliinlo.

c. Mbijo. lats dos sirquinutes. lam. 24, 2

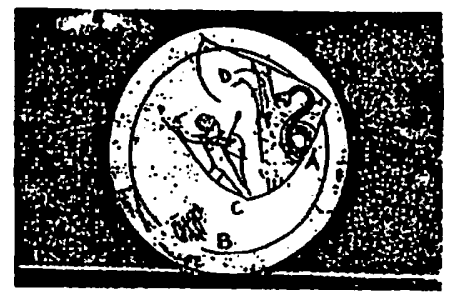

(cipa n"2. Sgg. Burms. I... op. cio., lím. A. 2 y 24, 1. 3.4

a. Serpiente.

b. Putaritice

a. Furister

d. ¿Planta de la vith?

(77) o las copas del pintor Sotades (figura 12), halladas en una tumba griega (78), a las que abajo nos referiremos. Además, conocemos el panal de miel de terracota hallado en una tumba púnica de Cartago, conservado en el Museo Lavigerie y los panales que aparecen en las estelas africanas del culto a Saturno (figuras 13 y 14), citados por Le Glay, de las que hablaremos más adelante (79). En el mundo griego, la leche y la miel eran ofrendas corrientes en los cultos a los dioses y también se utilizaban en Roma, donde eran corrientes las ofrendas a los Manes, las almas de los muertos, de miel, 
vino, leche y flores, siendo a menudo interpretadas, al igual que hemos dicho se hacía en el Antiguo Testamento, como símbolo de fertilidad y de vida eterna (80).

El panal de miel aparece a menudo ligado a centros religiosos mediterráneos ya en la Prehistoria. Su imagen perece encontrarse en la isla de Malta, tanto en el hipogeo de Tall Safleni, donde unos dibujos de forma exagonal, en rojo, recuerdan los agujeros de los panales, muy cerca del llamada "pozo de las serpientes sagradas" y en algunos templos, como en Tarxien, donde los agujeros múltiples hechos a modo de celdillas que se aprecian en algunas piedras podrían indicar que estamos ante representaciones de panales y estar relacionados con las abejas y un culto prehistórico a la Diosa Madre en la isla, adorada entre otras formas, como diosa-abeja. De aquí, tal vez, el origen del nombre de la isla: Malta, con las letras MLT que mucho más tarde encontraremos en Melilla, aunque también la hemos estudiado en relación con Saturno africano, Atis, Mitra y los comienzos del Cristianismo (81) pues Saturno era para los antiguos el iniciador de la agricultura. Y como tal fue adorado por las gentes de Cirene, considerándole como el introductor del cultivo de los árboles frutales. También era, según Macrobio (Sat. I, 7) el inventor de la técnica de la extracción de la miel. Participaría así Saturno de un doble aspecto: Bienhechor en la tierra y garante de la vida en el más allá. De ahí que sea portador de un panal de miel. Los antiguos africanos, incluso los anteriores a los púnicos, al igual que los actuales, eran grandes consumidores de pasteles y dulces hechos con esta substancia, de ahí que su gran dios, creador del

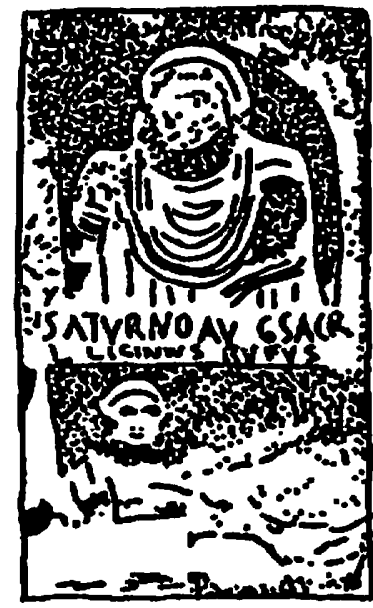

FIC.I:HA I:

Sg. Le Glay, M.: Satume africain. Monuments II, pl. XXXVi, fig. b. Sillige, $2 "$ milad, s. III d. C.., Dediención a Salurno.

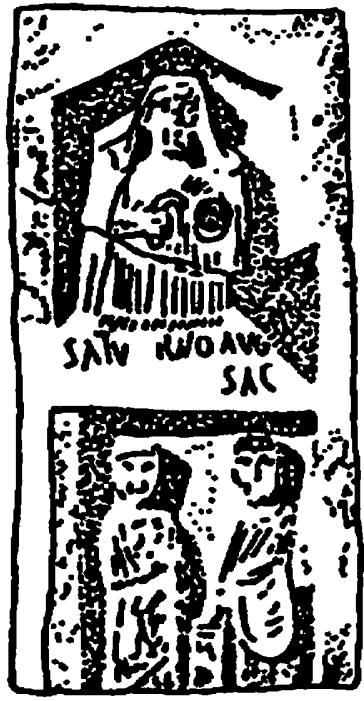

FIC:CRA It Dedicación a Saturno. Sillège, casa ancerdutal. Sy. Le Glay, op. ril., pl. xXXYl. 5. 
mundo, les hubiese dado la miel, y de ahí también, el posible origen del nacimiento de la leyenda. Así, la miel se relacionaba con Saturno, no solo en este mundo, donde les complacía y les alimentaba, sino también en el Más Allá, donde les garantizaba la vida eterna (82).

Esto explicaría la presencia de la miel entre las ofrendas de una inscripción púnica (83), y la del panal de miel entre los objetos acumulados sobre la mesa de proposición de una estela votiva ofrecida a Saturno por un habitante de Hr. es-Srira. También era la miel una ofrenda corriente entre los cananeos. Y así lo vemos en el Antiguo Testamento, ofrecida a los dioses de los que abomina Yahvé ( $E z$. XVI, 19), aunque estaba prohibida en el culto a este dios:

“Ninguna ofrenda que ofreciereis a Jehová será con levadura; porque de ninguna cosa leuda, ni de ninguna miel, se ha de quemar ofrenda para Jehová". (Lev. II, 11),

pero en II Cronicas XXXI, 5, se lee que figura entre los décimos, tal vez no considerada como dedicación directa a Jehová sino como alimento para los sacerdotes o para su utilización en el templo:

"Y cuando este Edicto fue divulgado, los hijos de Israel dieron muchas primicias de grano, vino, aceite, miel y de todos los frutos de la tierra" (84).

La miel jugó una gran papel en los cultos mistéricos de Attis, Mithra y en los paleocristianos, y en particular en las ceremonias de iniciación, (85), donde aparece como signo mismo de esta consagración divina que equivale al renacimiento y también en las ceremonias de los cultos de Isis, como relata Herodoto (86):

"No es la misma manera de escoger y consumir las víctimas en los sacrificios, sino muy varia en cada una de ellos. Hablaré del de la diosa de su mayor veneración (de los egipcios) y a la cual se consagra la fiesta más solemne, de la diosa Isis. En su reverencia hacen una ayuno, le presen- 
tan después sus oraciones y súplicas y, por último, le sacrifican un buey. Desollada la víctima, le limpian las tripas, dejando las entrañas pegadas al cuerpo con toda su gordura; separan luego las piernas y cortan la extremidad del lomo con cuello y las espaldas. Entonces embuten y atestan lo restante del cuerpo de panales purísimos de miel, de uvas e higos pasos, de incienso, de mirra y otros aromas y derramando después sobre él aceite en gran abundancia, entregánlo a las llamas. Al sacrificio precede el ayuno, y mientras está abrasándose la víctima, se hieren el pecho los asistentes, se maltratan y lloran y plañen, desquitándose después en espléndido convite con las partes de la víctima que separaron" (87).

Y en Djemila, el panal de miel figura en la mano del dios Saturno en las estelas que muestran, al lado de los padres, autores del sacrificio, a los niños que han sido consagrados y ofrecidos al dios, y aunque, evitando su sacrificio cruento, se les sustituya por un animal, ellos son los grandes protagonistas y beneficiarios de la operación sagrada. Esto se ve claramente en la escena en la que está Saturno presentando el panal de miel, sentado. y el niño de pie, bién al lado del altar, entre su padre y su madre, bién a su lado (88).

Después de las pruebas a las que el mystes era sometido al iniciarse en posibles misterios del culto a Saturno (89), se cree que recibía una bebida elaborada a base de leche y miel, como también se hacía, entre otros, como ya veremos, en los misterios de Attis (90). La miel que gustaba a los dioses y que como un recién nacido el mystes come en su iniciación, aparecería así como un lazo de unión entre el iniciado y su dios, símbolo del renacimiento recibido.

Tal vez a esta bebida mística puede hacer alusión, en otro culto mistérico, el de Mithra, la inscripción descubierta en el mitreo de Santa Prisca, en Roma, en la que se lee en la línea 2 del graffiti existente sobre el lado izquierdo del nicho de culto, las palabras siguientes (91):

-dulcia sunt cicata avium, sed cura gubernat pie rebus renatum dulcibus atque creatum" 


\section{que Vermasseren y Van Essen traducen}

¿dulces son los hígados de los pájaros, pero el cuidado (de Mithra) guía a aquel que es piadosamente renacido y creado mediante las dulces cosas"

explicando que esta palabra, renatus, significa el renacimiento del iniciado tras la muerte ritual. Y que dulcibus hace alusión a la miel, a la que los teólogos dan simbolismos diversos (92).

También, en estos misterios mithraicos, el iniciado, al recibir el grado de Leo, se purificaba con miel la lengua de todo pecado. Y también se utilizaba la miel al celebrarse las ceremonias con las que los iniciados recibían los grados de Persa y Heliodromo, no conociéndose, al menos hasta ahora, la utilización de dicho elemento en las ceremonias del grado de Pater (93).

Asimismo, el culto paleocristiano utilizaba en las ceremonias prácticas similares. Y así, tras su primera comunión, el neófito recibía, según Tertuliano (94) una bebida de leche y miel. Ello explicaría la presencia de una abeja sobre el mosaico de la pila bautismal de Kelibia, en Tunez, por "simple trasposición simbólica", según Curtois (95). A este simbolismo se le puede añadir otro, según Février y Poinssot (96). Según estos autores, la abeja, de la que nace la cera que da origen al cirio pascual, sería a la vez la imagen de la Virgen, como el cirio es la imagen de Cristo que ilumina a los hombres y la imagen del justo que nace a la Iglesia por el bautismo.

Aunque, como dice Le Glay, el culto de Saturno no es un verdadero culto mistérico (97), al igual que en las religiones de Attis, de Mithra y de Jesús, las ceremonias de su culto debían completarse por una cierta forma de comunión, aunque esta práctica no se recoge en ningún texto y tal banquete no está representado en ningún sitio. Pero la presencia de un panal de miel en la mano del dios, figurado en los relieves y estelas mencionados, demuestra que no se trata de un simple símbolo ctónico sino de un atributo divino según Le Glay. En nuestra opinión, esta representación indica por sí misma, sin necesidad de más ceremonias, de las cuales no existe prueba documental, la utilización de la miel con una idea de inmortalidad, es decir, se trata de un signo o señal de la inmortalidad que el dios confiere 
a sus fieles, lo que daría, así, una significación más profunda a esta representación en los relieves al panal de miel. Este objeto, pués, hace a Saturno dios del renacimiento tras la muerte y crea un lazo indisoluble entre los niños consagrados a él, representados en las estelas, a los que el dios ofrece la comida de inmortalidad y el dios que la concede, como una esperanza en que la vida mortal continua más allá de la muerte y un día volveran de nuevo a vivir una vida terrena, renacidos por la virtud del dios. Y pensamos que esta idea se expresa por medio del símbolo del panal de miel, puesto que dificilmente podría representarse solamente por la miel de una forma facilmente identificable e inequívoca.

LA MIEL, LA ABEJA Y LAS DIFBRENTES DIOSAS ADORADAS EN EL, MIDITERRANEO

ARTEMIS

La miel "deifica". lo que quiere decir que, en cierta manera, pone en contacto con la divinidad y transmite sus cualidades y propiedades más preciadas. Y uno de los atributos de la divinidad más deseado por el hombre era la inmortalidad, lo que hizo a la miel ser considerada como "alimento de inmortalidad". Y de aquí, también, su conexión, no solo con diosas como Artemisa de Efeso (figura 15), tal vez una primitiva diosa-abeja de tradición prehistórica en Anatolia y Asia Menor, en algunas de cuyas ciudades está representada la abeja en las monedas (98) (figura $8, \mathrm{n}^{\mathrm{a}} 6,7,8$ ), o la misma diosa representada en las placas de Rodas (figura 16).

Asimismo se relaciona con Hécate, diosa afín a Artemis, que otorga la prosperidad material pero también terrible diosa triple, del cielo, la tierra y el infierno, diosa de la luna y gran maga que preside los hechizos; con Plutón-Hades, rey de los infiernos, en su origen un

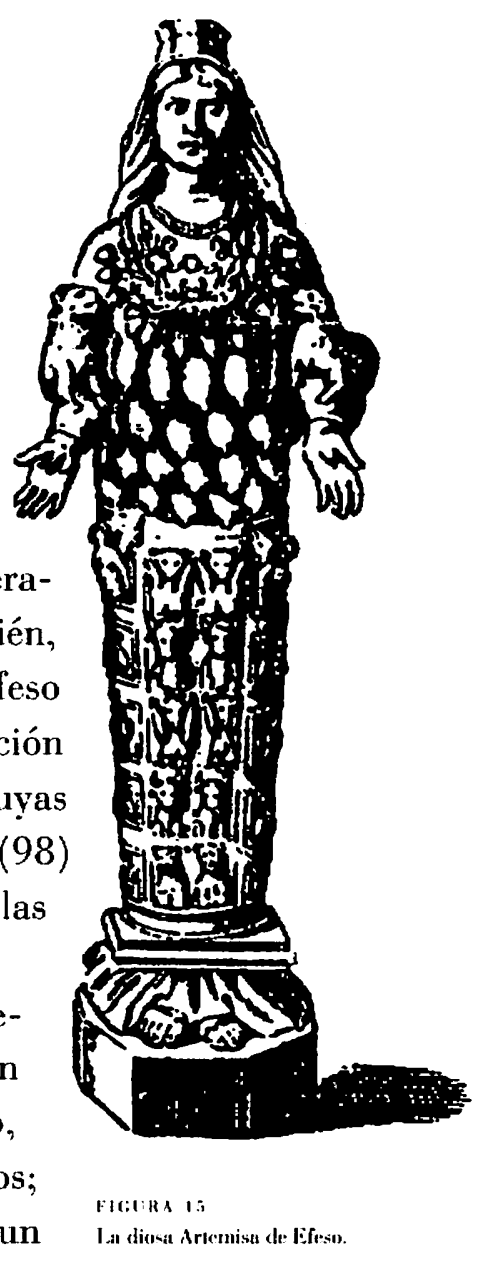




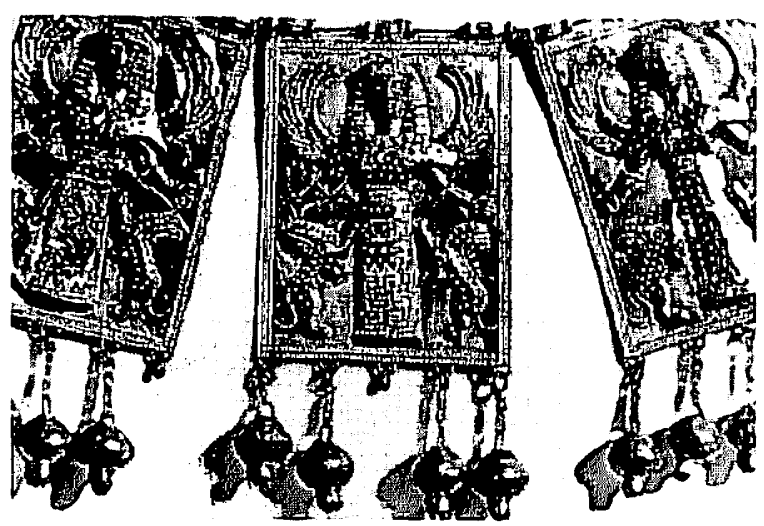

HIt:I R. I",

Placas de Roulas. Museo Británion.

dios agrario y con Saturno-Cronos, antiguo dios del Tiempo, patrón de la agricultura y divinidad ctónica relacionada con la fertilidad y, al mismo tiempo, con la muerte y laresurrección, así como con Dionysos, Attis, Orfeo y tantas otras divinidades cuya sola mención parece hacerse interminable, además de la serpiente, animal ctónico por antonomasia, a menudo acompañante y símbolo de estas deidades, con las que parece representada frecuentemente (99).

DEMETER-PERSEFONE:

Y también está ligada con las divinidades del más allá, ya que sabemos que la miel, junto con la abeja y todo lo referente a ella, tenía un gran papel en el culto de las divinidades ctónicas (100) como Deméter, ligada por Virgilio a la leyenda de Melissa, mujer a la que la diosa había revelado los secretos de la obtención de la miel, que por conservarlo murió despedazada por sus conciudadanas, y cuyas sacerdotisas llevaban el nombre de "Melisas (101).

También está relacionada con Perséfone, diosa de los infiernos y compañera de Hades, hija de Zeus y de Deméter, según la tradición más corriente, aunque otros mitos la hacen hija de Zeus y Estige, la ninfa del río infernal. Raptada por Hades, su tío, motivo la búsqueda por parte de su madre Deméter, que más tarde daría lugar a los misterios eleusinos, en los que se celebraban, junto con los ritos agrarios, ceremonias de inmortalización (102).

LA DIOSA MLADA HISPANA ASTARTE

A veces existen ejemplares exentos, no solo en Creta sino también en el Sur de la Península Ibérica. Otras veces, abejas o personas disfrazadas de 
abejas se ven en algún sello micénico (figura 17). También encontramos numerosas figuras aladas femeninas, al parecer de Astarté o la "Señora de los Animales" (figura 18) incluso en la Península Ibérica tanto en la cerámica ibérica (figura 19) como en piezas exentas. Así, la diosa alada de

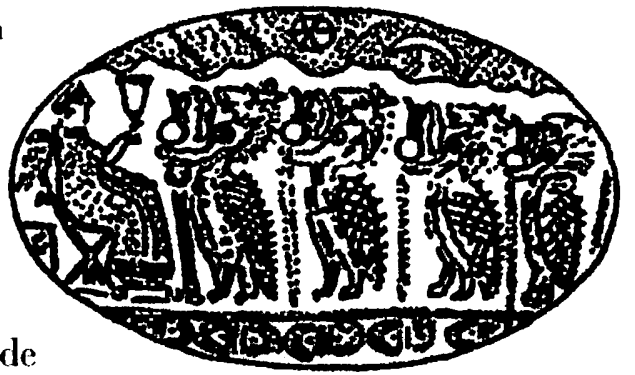
El Berrueco (figura 20) o la de Santiago de la Espada (figura 21), además de otras sin alas (figuras 22,23 y 24).

GONCIISIONES

Nocil B.t

Sortija de oro procerelente de Tirinto. $A$ la derrolta uma diosa sentada con un ritón en su mano. Detri- do sos trono on ve un paijaro. Cuntro demonion an aress disfrazados con forman de alojase necrcan a la diosid.

ASTARTE Y SU CULTO EN EI. MEDTTERRANEO: LA ABEJA, IA IAI,OMA Y

LAS DIOSAS ALADAS. LA BARAKA Y LA CONTIYLIDAD DE IOS CUITOS ANTIGUOS

Así pués, hemos visto que existe una especial asociación entre la mujer y las abejas, (103) donde refiere que según una tradición que se remonta a Hesiodo, la abeja significa la esposa de los dioses y en la mente de los griegos, la melissa es el emblema de la virtud doméstica femenina. El nombre Melissa para una Hespéride no es raro (104). Hubo muchas Melissas en los relatos mitológicos. Entre otras podemos anadir las Melissai, hijas del rey-abeja de Paros, visitado por Demeter cuando buscaba a Perséfone, a las que la diosa reveló los misterios de su culto y son el origen de las Tesmophorias, en las que las mujers que participaban llevaban el nombre de "Melissas". O la hija de Meliseo, rey de Creta cuando nació Zeus, que alimentó al dios con miel y fue la primera sacerdotisa de Rea (Cibeles). También con la raíz - mel se conoce a Meliteo, hijo de la ninfa Otreis y Zeus, que temiendo

FICIRA I

Vaso de bronce Cirneckwyl isuiza!. VI a. C. Ashtart, atada, lleva el cirlo solure su cabeza on forma de ingula. A los lados las dos entzienten celestes y cuatro lone- que figuran las cuatro apariciones steesivas alel ploneta

Venus, Sạ. Du Mrsnil du Buisson.

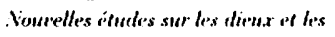
mọlles de Cumain. Brill. I cristen. 1973. p. 150. 


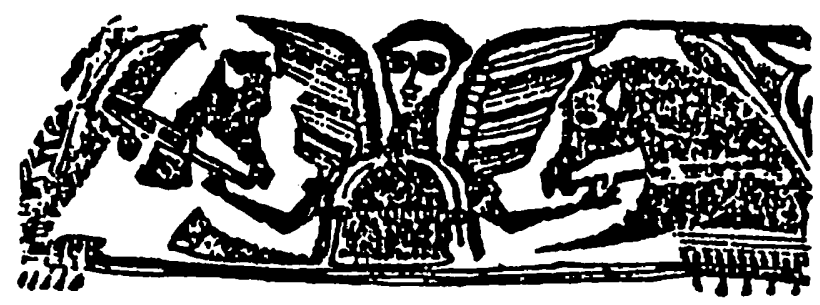

FICI:RA 10 Representaciones de Asturlé alada sobre la cerritmica de likhe (Colection Rarmess follepués).
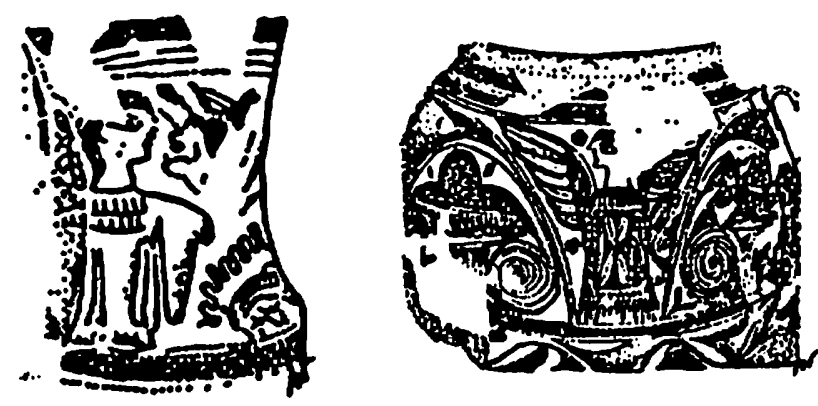

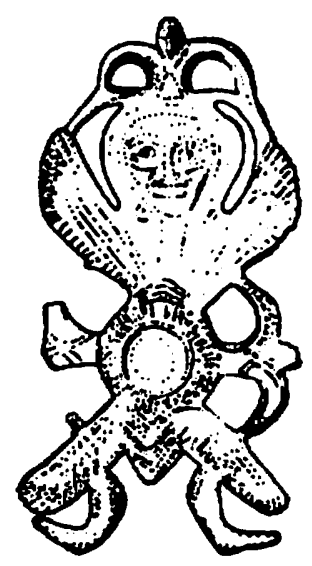

FIC:1 Ki 20

Diosa ulada de lia berrueco.

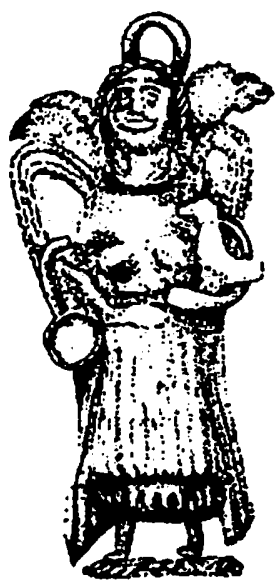

FICIRA 21

Santingo de la Fsparla. Diosa alada. 
la cólera de Hera, lo abandonó en un bosque, pero Zeus hizo que fuese encontrado por medio de un oráculo, por el pastor Fagro, hijo de la misma ninfa y Apolo, que le alimentó con miel. Es el fundador de la ciudad de Melitea, en Tesalia (105).

Y también hemos visto que esta relación con la miel puede adscribirse a una divinidad femenina que, como diosa de la vida y de la muerte, debió ser adorada por todo el Mediterráneo, y con él, en Melilla, ciudad fenicio púnica inserta en los circuitos políticos, económicos y religiosos del mundo antiguo.

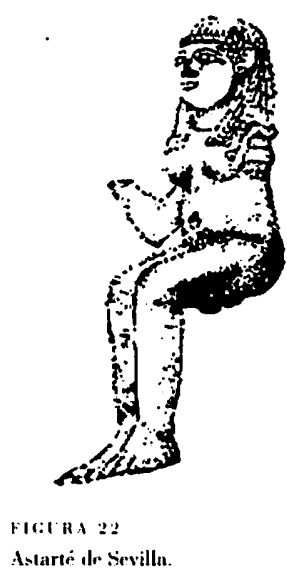

Si a eso añadimos la noticia que comentábamos al principio, acerca del hallazgo en dos ánforas del Museo de Melilla, según Claudio A. Barrio, de la inscripción del antropónimo BOB ASTART, que puede traducirse como "en las manos de Astarté" o "perteneciente a Astarté", veremos que no tiene nada de extraño el referirnos a la presencia del culto de la diosa por estas latitudes y al hecho de que fuese protectora tras la muerte, señora de la vida eterna y también, como diosa ambibalente, dadora de la muerte, diosa temible que propaga las enfermedades, a la que hey que aplacar, a veces, como en el caso de Saturno, Ba'al o el casi posiblemente inexistente Moloch, con sacrificios humanos.

Todos estos datos enlazan con el sentimiento de proteccion ante la adversidad que se busca con amuletos o los mismos símbolos fálicos protectores, de lo que es una buena representación el vasito que fotografiamos hace años en el Museo de esta ciudad (figura 3) o el espejo de bronce procedente del mismo Museo (figura 25), espejos de los que ya hace años escribimos que podrían tratarse de símbolos de la misma diosa de la fecundidad, de la vida y de la muerte,

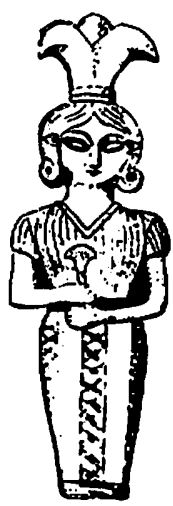


FICIRA is

Fragmenuos de espejo.

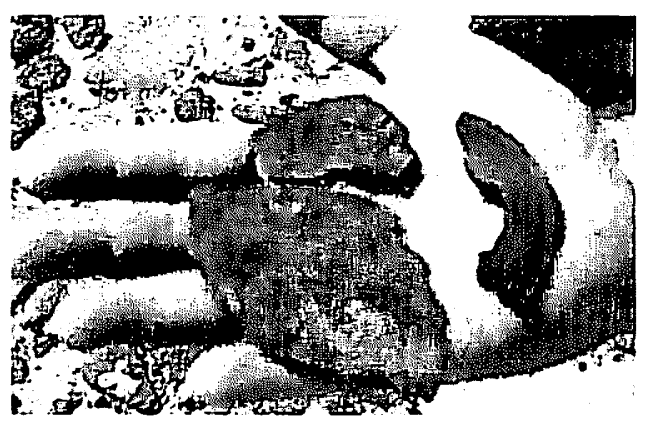

como una forma de representarla en la tumbas y símbolo de la vida eterna que dicha diosa o su culto procuran (106). Y la protección contra "el fuego de la enfermedad", "la diosa abrasadora" o "La Maga", nombre que quiere verse también en el tan repetido nombre de Melilla, el que lleva una divinidad maléfica, la otra cara de la diosa de la vida, que es al mismo tiempo la diosa de la muerte.

Pervivencia o continuidad, pero en el fondo, necesidad humana de protegerse ante la adversidad y símbolo de la misma continuidad del hombre sobre estas tierra, con sus mismas creencias y necesidades a lo largo de la Historia, son las creencias actuales constatadas por otros estudiosos melillenses, sobre los cultos en cuevas, las piedras y su poder fertilizante, que también constatamos unido en el mundo antiguo a diosas como Gibeles, los Yenún maléficos, suerte de manes $\rho$ espíritus de los muertos que salen de su sepulcro para molestar a los vivos, como los Lémures o Manes romanos y, sobre todo, la Baraka o poder sanador, don divino, estudiado para la comarca de Ikelaia por Lucas Calderón y Adela Ponce.

La mejor conclusión que desearíamos hacer constar, por último, es la necesidad de más datos materiales. La importancia de las excavaciones sistemáticas. Y la escasa fiabilidad de los datos sobre los que hemos apoyado nuestras conclusiones, llenas, como todo habrán oido, de dolorosas conjeturas, fruto de las escasa noticias fiables que hemos manejado para llevar a cabo nuestro estudio. Pero que esperamos puedan servir de ayuda a futuros investigadores. Y queremos aprovechar este marco incomparable para hacer resaltar a nuestros oyentes la necesidad de preservar nuestro pasado, de llevar a cabo estudios sistemáticos, de concienciar a todo el mundo del valor de los restos arqueológicos, porque nuestro pasado, maestro del futuro, está en ellos. 
1 Solbre esie tema la bibliografín es amplísima. Aute la imposibilidad de refierirnos a toclos los arrículos ofr.

2 Subre la descripción de esta provinuia por Pomponio Mela cfr. COON\%.NI.BIFS CiRAVIOTO. E.: "La deseripuiou de Manritania Tingitana en Pomponjo Mela", II (WEC, Madrid, LNED 1995, t. II. II. $259-265$.

3 (if. sobre los fenicios en Hispmnia, además de lus (rabajos citados en la Bililingralía general, el libro de LOPEZ (ASTTRO). I. I.: IIspania Poena. Los fenicios e'n la Mispania romona. Fd. Crítica, Barcelona 109+ notas 36 y 37, p. 290 . Sobre la finauciación de la segunda guerra púnica cf. id. p. 8t-97. Tambien VAZQUEZ, HOYS, A. M":

" $\Lambda$ grumos factores económicos de la segunda gurrra púmica y su presencia actunl su el Si español", Hamnibal Pysrmaemum Tronsgreditur, XXII Centenari del Pas d'Annibal pel Pirineu, 218 a. J. (..-198:2 d. J. (.., Puigeerdá 1984, p1). 17:3-188.

4 Sulure este tema of. las ponemeias de los

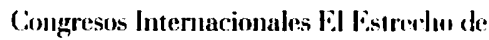
Cibraltar (CIEG), celebralus rn (ituta en Noviembre de 1987. Aclas editudas rea Madrid, UNED, 1988 y el serundo, Centa. Niviembre 1009, ed. en Madrial, L.Vlils, 1905, sobre todo las conclusiones de: FFIRNANDEZ MIRANDA, M.-RODERO, A.: "El Círculo del Estrecho veinu años después". II (WC, Madrid, UNED 1995, pl, 3-20.

5 (ifr. las ponencias al respecto de las Aclas del I Congreso EL Estrecho de Cibrultor. (ieuta. Nov. 1987, UNED, Madrial, 1988. Lstos contuctos ya tenían lugar en el Veolítion sg. ML ÑOZ AMILIABIA, A. M": "I cos contactos en el área del Estrecho durante el Veolítico". cfr. en dichas Actas, 1988, 1. I. pp. 183-182. Fin roca del reinado de luba ll y Polomeo en Maurilania (S. I a. C.-S. I d. (:.) se produciran una serie de cirrunstancias concretas que unieron económica y religiusaneme Carthago Nova, bu H lispanin y Mauritunia, en el Norte de Afrien, continunnelo asi las relaciones que. posiblemente muca se interrumpiermo. deste III lejano como minimo II milenio a. (:.

6 BEI.TRAN, A.: "Iuba Il y Ptolomeo abe Mauritania, II viri quinquennales de Carthago Nova”, en Coesarougus/a 51-.52. 1980 p. 1:3:3-1+1; también 1ra1a el tema de las mugistraturas MANGAS. I.: "luba II de Mauritumia, magristrado y patromo dor ciularles lis spanas". Actas red / Congreso sobre el Estrecho de Gibrallar: Madrid. ( i. NEI) 1988. 1. I. p. 731-39. (.fr. muestra explicacion en VAZQLEZ IOSYS. $A$. M": "bl eomercic entro Ilispania y Mauritania y el Templo de lleraceles Melkart de Candes". en II Cill:C, Madrirl, 1995, pp. 320-342.

7 LIPINSKKI, L.: “'Tartessos el la stèle de Nura”, en Sigando Congreso Intemacional de estualios sobre Kes culturas del Mediterrineo Occidental. Barcelona 1975, pp. 71-77: I.IPINSKI (od.) State and Temple Econom! in the Ancient Nerer East II. Ol.A 6. I ouvain $1979,1.597-604$; id.: "I Le rôle de (indes dans l'implantution phénicienne en lisprugm:", AO IV, 1986, p. 187 ss.

- irl. "Quelepues aspects du commerese ì lomgune distance des syriens et des phénicions" en Momenti precolomiali nel Mediterrumeo Antico. Acatemia Belgica. Istituo perer la civiltà fenicia e punica. Roma 1088 pl. 227-233.

8 lESTRABON III. 3, 5, tal ver Iomamla de Posiclonio refiere que los Gaclitanos, solsre la fumdución de: Gadeira, recuerdan los Gaditanosi un cierto oráculo que habrían recibido de Melkart y que se realizi al tercer intento. También el relato mítico de la fundación de: Tiro incluido en las Dionisianeas de Nonno. 40. vv, 443 ss. Fiste autor. nacido en la Tebaida egipcia a fines del S. IV d. (C. se refiere a que Melkart despierta a unos hombres "nacidos de la 
tierra” y les “inspira su orácula”: les ordena construir una nave, hacersa a la mar y fundar una ciudad sobre dos recas flotantes. Melkart proporciona a los inspiratos las claves para reconocer las rocas flotantes iumortales (Ambrósiai) destinadas para la fumclación, dándole asimismo instrucciones para realizar el ritual de asemumiento. En las rocas les dice que veran un ulivo que arde sin consumirse, con uma strpiente eurollada en su tronco y un águila en su copa, indemmes al fuego. Al sacrificar el aguilis, las rocas quedarian fijalas. lil prodigio se ve grabado en un relieve grecorromano descubierto en Tiro. Museo de

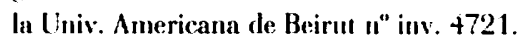

Posihlemente el recuerdo de las tres expediciones relleja una búsquerla sobre el cerreno de la ubicación más finvrable para la ubicación de la colonia tirin: ajustamla posteriormente al designio divino las peripecias de los colonizadores. Por ello no nos cabe duda de que se trató, como en los masos que conocemos en (irecia, de una empresa econónica propiciada por el templo de I Terakles-Melkart de: Tiro. Sobre los orńculos griegos ofr. PARKE. H. W.: Greek Orecles. Londres 1967; p. 44 ss.

- Cracias a los documentos del templo de la diosa Ban en Lagash, núcleo de la Cindad-Estado, ofr. BOGAERT. R.: Les origines antiques de la Banque de dépôt. line mise au point d'une esquisse des operations de banque en Mésopotamie. A. Wi. Sijthoff, Leyde 1966, p. 4:3-63.

lin general, los dioses de las ciudades eran los propietarios más importnutes de tierras, así Vingirsu en Lagaslı, Sin en (Jr, linlil en Nippur y Anu en Cruk. También en Asiria, a mediados del s. XIX a. C. las cartas conservadas contienen alusiones a los pagos a los dioses Adad y Assur, a los mercaderes sobre los que el dios tiene un derecho de garantía o fianza y a los intereses de los rempliss
Cifr. CARliLLI, Les Assyriens p. 252-257, solıre la urilización por los merenderes de los ikribî als: un dios, que no son depósitos propjiamente dichos sino bienes votivos sobre los que los depositarios guardaben ciertos derechus. Cfr. Bogaert p. 48. n. 25. Sobre los templos babilonios y la primacía del dios del sol ren estos negocios efr. IIARRIS. en JCS. 14, 1960. p. 126-127. Entre los quic pedian y recibían el préstamo del templo se encuentrun comerciantes que tienen, m estos latsos, un acreedor, para una empresa comercial. listos préstamos se llamaluan Iabba " lappôtum. C.fr. LliTZ. II. F.: "Babilonian Partuership" Jomm. of. Econ ans Bus. Ilist. 4. 1931/32). 552-570.

10 BOG.NERT'. op. cit. p. 130 y ss.; id. Bremque of bronquiers dans les cités greonues cit. en p. $1: 30$ ı. 3.

11 la seguridad de sus depósitos era lal yue. muchos autores griegos, desde Aristofanes en el s. V' a Elio Arístides en el s. II d. (: hacen un elogio de ella. También los lemplas de I lera en Samos, Apolo en Delfos. Atenea Iindia en Rodas, de Atenea Aléa en T'egea y otros tenían cámuras de depósim y cajus fuertes a disposición de sus licles. Orros santuarios, como el templo de Apolo en Délos, han presiado sus fondos dispunibles a Estados y a partirulares. Las mismas operaciones se atestiguan para el templo de Zeus en Olimpia. de Artemis en Sardes, de Atenea en Priene e llion, de Apolo. Aconea y Artemis en Halicarnaso y también otros santuarios menores, como los le: Mirrinumte en el Atica, el de Distus cerca de liretria, el de $\Lambda$ polo en Caraia, $m$ la isla de Cíos, etc... lian hecho frucifienr sus fondus prestándolos a interes. También alyumos cemplos emitieron monedas, acuñamdo sus depósitos de plata. que llevan sll efigie o su leyenda. Por ejemplo, los de Ofimpia y Heraia, el de Apolo de Didyme, en Miletu y las emisiones de la Amfictionía de Delfos. 
12 Tesis que ya defendimos en: "I lixus en el panorama religioso fenicio de Oecidente". Colloyue International sur Lixus: Bikan at perspectives. Institut National des Siciences de l'Archéologie et du Patrimoine. Ministère Des Affaires Culturelles. Rabat, 8-11 Nov. 1989. Maroc. En prensa. Esta misma Tesis la sido defendida también por mumerosos autores. Cfr. BLNNES, G.: L'exprension phéminionne en Médilerranée. Esssri d'imlenprétation fondé sur urne analyse des traditions littémires. Institut I listoriøue: Belge de Rome. Bruxelles-Rome 1979. EX España efr. RLBIO RIBERA. R.: " 1 .a funcion de Cádiz en el periodo precolonial fenicio en el Estrecho" Actas / Congrarlo EI Estrecho de Gibraltar cit. p. +1)7-418: WAC;VleR, C.: "Gadir y los más amiguos asentamientos fenicios al este clel estrecho", en las mismas Ac1as, p. 419-428; AIV, VR. J.: "I an precolonización y el trálico marítimo en el Estresho", en las mismas dotas. p. +28-444: también RODRIGLEZ FERRER. A.: "El templo de I lercules-llelkart. In modelo de explotación conómica y prestigio prolitico". Actas I Congreso dr Mistorio Antigure. Santiago de Compostela 1988, p. 101-110. Fin algunos casos, comso a Cádiliz. lisirabon recuerda que fineron enviados por III oráculo (Estrabou III, 5. 5; Dionloro V, 20, 2). Y a Utica, citado por Plinio (PI.I.VIO, VII XVI, +0). También las fuentes epigrálicas: Nora, donde se ha encontrado una estela fenicia (CIS I. n" $1+t$ ).

efr. I.IPINSKY..: "lartessos a la slele de Nora”, en Segundo Congreso Internacional de estudios sobre las culluress del

Mediterráneo Occidental. Bareelona 1975, pp. 71-77. pp. 74.

13 (:NTAS. P. La céramique pmiquer. Paris 1950 p. 582-83;.

14 REBblilidT, R.: "Hélène en Fygute et le Romain égaré, en REA 1. I XVIII. 1966. p. 247-2481966, p. 245-26:3; 1ambién BONNEIT op. cit. p. 161.
15 A pesar de que carecemos de pruebas arqueológicas para probarlo, daclo el esiato de destrucción de los establecimientos lenicios cononidos y que dichas transactiones no se resteñarian en materias duraderas, por lo que: no tenemos constancia de cellas.

$161)|O|)() \mid R() \times X, 14,2$.

17 Incluso, tal ve\%. podríamos aventurar taue, si los templos con oráculos eran centros de poder, Inles romo Delfos en Crecia, Donlom en Epiru y Curdion en Frigia, el apryo ile lus dioses (sus finanzas) ayudó a Alejaucloo a concuistar el mumdo. tanto de l leracles como Apoluo \%eus. No olvidemos, lampenco. las extrandiuarias consecuencias ecomimiras de la colonización griega del Mediterrámeo y que la comquista del lunperio Persa ahriic unas extraordimarias perspectivas económicas al mumlu antiguu).

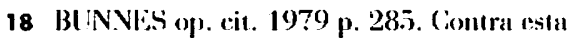
opinión, que seguimos, está la de MARIN (IBBA.I.OS, $\mathrm{Y}^{\mathrm{a}}$ C.: "Reflexiones en torno al papel economico-político del templo lienicio". Homenaje a J. .M" Blízquez II. Madrid 1003. p. 349-361. que se mefierte en esie 1rabujo a los opiniones de mumerosos invesligatores que la sustentamos. Cinmu esta atuturn indien al fimal de: este artínulo. hace lalu, evidentemente. countiutur investigando, a fïn de contormar estos sugerentes indicios y en este sentido, de: invesigacioul e hipótesis para avanzar murstras investigaciones emilimus nues ras opiniones que tal vez el tiempo o las fuentes confirmen o nieguen. Lo que si es evidente es la cousexión do la monarquía rom la religión, ya desde época paleobabilónica.

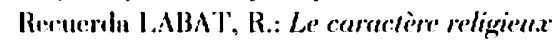
de le rourminé assyro-babytonienne. París 19:39. pp. 202 y ss.. que la ley era revelada al rey por los dioses y que él juzgaba en su nombre. También l lammurabi declara "reinar" para hacer resplandecer el derecho solvrı el pinis. Cifr. asimismo GOLIKOWSKY. op. cil. p. 278 , н. 11 a 19. 
19 También en su visita al oráculu de Amós, en Siwa, Alejandro Magno es saludado como hijo de Amón. Esia relación de los reyes y los dioses, seguramente, no solo era de caracter divino e incluía una relación patrimonial, de caracter económico.

20 La fecha atribuida por Plinion a la fundación de Utica está en función de la que auribuye a la fundación del templo de Apolo (PLIVIO, NH XVI, 40) y también en Paphos y en Citera, la sola noticia sobre la presencia fericia que da Ferodoto (I, 105 ef.

PAUSANIAS I, 14. 7) es la funclación de los templos de Afrodila. También en Thasos, (HERODOTO II, 44; PALSANIAS V, 25. 12; EUSTATO a DIONISIO EI, PERIEGETA. 517), lalysos, DIODORO ( $V .58,2-3)$, Menfis, HERODOTO (II, 112), De Cantopo. Helánico habla de esia zona como de la "bowa hercúlen del Nilo". I IELLL.. 4F $153 \mathrm{~J}=$ EUSTATH., ad Od. IV 228 y también Estrabón, XVII, 1, 18 y Tácito, Ann. II, 60. Asimismo, una instripción (IGRR 1 1092) está dedicada a Zeus Hélios, el gran Serapis de Canopo, en una esiatua que representa a Herakles Baal el Invencible dedicada por u Escalonita, clr. BONNET, C.: Melkart. Cultes at mythes de I'Héractes tyrien en Médilemanée. Studia Phoenicia VIII, Presses Universitaires de Namur, 1988, p. 160 y 131. cfr. BUNVENS. G.: L'expansion phénicienne' en Méditerranée. Essai d'interprétation fondḱ sur une anabse des traditions littéraives. Institut I listorique Belge de Rome. Bruxelles-Rome 1979, p. 283. El t lerakles de Cádiz, como el de Canopo, con seguridad no es el héroe griego, Herodowo (II. 93-94). La identifinación entre el Herakles de Canopo y Melkart la hace, entre otros, Pausanias, en un pasaje en el que refiriéndose al poblamiento de Cerdeña, menciona sl nombre del jeft: de la expedición, Sardos, y le califica de hijo de Makéris, "rebaulizado Herakles por los egipcios y los libios", y termina por identificar a Makeris con Melkart, concluyendo con la identidad entre ambos diuses.
A Occidente se craslató un patrón institucional existente en las ciudades fenicias de la costa camanea, y como dice $\Lambda$. M. Bisi, la acividad de los fenicios se encuadra en un ambiente que ha absorbido la herencia de las gentes crumaneas del II milenio, continuando los patrones de organización comercial a larga distancia aplicados en las ciudades sirias como Mari, Ugarit, Alalak, o antes, en Ebla

21 VAN BEIRCHEM op. cit. 1967, p. 330. También en Roma, en el Foro Boario, los fenicios inpusieron, con el culto de su dios. uma disciplina probada por una práctica de mercados interuacionales. Alrededor del altar erigido en el Palatino, el respeto a la palabra dada y la estricla aplicación de los contratos debió prevalecer sobre la violencia y el robo. como afimma Diodoro (IV, 19, 1). haciendo referencia al papel civilizador que los antiguos prestaban a Herakles, también intuuable a su rolıle tirio, Melkart.

22 FERNANDEZ DE CASTRO Y PEDRERA, R.: "I as necrópolis púnica y romana de Melilla", Aldabr 9, 1987. pp. 127-134. (id. en Africa, Madrid. Junio 1950, n" 102, Pp. 7-11 (257-261).

23 VAZQUEZ IIOYS, A. M" : Dicciomario de símbolos y términos mágicos. INED, Madrid 1994, s. v. "color rojo", p. 69.

24 VAZQLEZ HOYS, Diccionario cil. p. 243.

25 CHEVALIER, I.-GHEERBRANT, A.: Diccionario de los simbolos, Ed. Herder, Barcelona 1986, pp. 332-333.

26 Sobre este tema efr. DI:TIENNE, M.: Los Jardines de Ademis. La mitología griega de les aromas. Ed. Akal. Madrid 1983.

27 Solore esta diosa cfr. BONVIET C:. "Astarté. D'une rive a l'autre de la Méditerranée". Wurcia 1994. pp. 143-158, con toda la bibliografía anteriou.

28 Solore esias diosas cfr. LOPEZ, I.-SANMARTIV. I.: Mitología y religión det 
Oriente Antiguo. I. Mesopotmmin y Egiplo. lial. Ausa, Sabadell, 1993. [1]. 301. Inamua sumeria / Isluar acadia es la divinitad femenina más importante del panteón babilonico. Fra tridimensional: Erótica y atractiva diosa del amor y del sexo. aparecía desmula: sanguinaria y despiadada diosa de la guerra y la venganza: y con alas, commo astral, Venus celeste. En ella confluyen los diversos arquetipos femeninos. exchyendo la maternidad: La divinidad del anoor ni concebia ni daba a luz. A fo largio del II milenio tienden a multiplicarse los epítetus maternales, aunque se trata de unit modia. Lilla es la personificación divinizada de los femenino. Su caracter astral es rival del sol. Shamash ỵ la luma. Filla es la Vollus matutina. la Estrella que se levanta antes quie: al sol.

29 (Cr. Mitología y religión del Antigno Oriente, lil. Eusa, Sabadell 1993, t. II / 2. Ip. 245-247.

30 Mitologín y religión del Orientr antigno. t. II /2. pp. 125-126. K'Tl 1. 13.

31 I.IZON NOCLE, J. M": "I As hippoi gaditanes". Actas I CIEC; Mudrial 1988, Pp. $4+5-458$.

32 DF:TIENNE. M.: "Le mavire dMh"ma", IIIR 11, 1970; ANTI, C.: "Allenea Marina e Mara". Monmenti Antichi XXVI. 1920. $2 ? 0 \mathrm{ss}$.

33 FII OON DE BIBLOS, apud l: ( SI:BIO I)H:

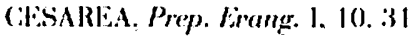

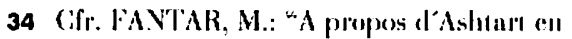
Médiceranée occidentale", RSF 1, 1973, 19-29; DELLA CORTL, F.: "I. luno-Astarté virgiliana", en Alli dedl Congresso Internazionale di Studi fenici a" punici. vol. III. Rome 1983. pj. 651-660.

35 (:fr. IIVID)EBERG-I lansen. IF. O.: La déesse TNT. line étude sur la religioun camunéo-panique. (inpenhangue 1979).
36 (fir. IIAI IF, C.: "L'onomastique punic|ue it Carliage", Kharlago 12, 196:3-t, Pp. 6.3-146.

37 cf. RIBIC:IIINI. S.: "L haruspicina fenicion-punica e la divinaziones a Pato". (F21, 1989. p). 30?-31?.

38 S(ANDONE MATTHAE, G.: "l lathor

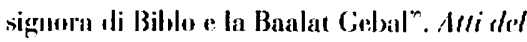
"/ Comgresso Internazionale di studi fromici prumici, Roma 1991.

39 G'TLRRERO AYLSO. V.: Narios. nareganles en las rutas de Baleneres durante la l'rehistorica. Palma de Mallorea. lid. lil Tall. 1993. 1.25

40 IIOR.NIIJ.. J.: "The role of Birds in Liarly Navigation", en Antiquili $20,19+6, \mathrm{p}$. 1+2-1+9: acompañado además de uma experiencin cuyos resultados se induyen en al mismo trahajo, que realiza con I. M. Coin. I.L\%ON. I. Ma-COIN. I.. M.: "I.a navegación pre-astronómica én la Amiginodad: utilización de prájaros m la la orientación naútica", Lucentum 1986. 11). $6.5-85$.

41 IIEVOFONTL, Oeconomic, VIII.

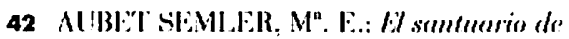
Is C'uierum. Trab. Museo Arq. An Ibizal 8 , 1982.

43 SAN NIC:()I .AS PLDRAZ. M. P.: ('orpus de errarolas de lbiza: ALMACBO (;ORBLiA.

V. J.: (orpus de las lerracolres do Hiza. Madrid 1080, lám. CX.

44 POVlid)A NAVARRO. A.: "luno Caelestis en la colmuin hispanorromana de Ilici", EYF 8 , (INIED, Maulrid. 1995. pp. 357-369.

45 AVIliNo. (). N. 31+-315

46 BI .A\%() T.Z. J. M": Religiones prerromamas, in P'rimitivess religiones ibéricus II. Madrid. 198:3, p. +1 .

47 (). M. :322 
48 PLINIO IV, 120

49 O. М. $31 \overline{5}-317$

50 POVEDA NAVARRO, $A$. en ETS 8, p. 358. Del mismo autor "Primeros datos sobre las influencias fenicio-púnicas en el corredor del Vinalopó (Alicante)", El mundo púnico. Iistoria, sociedad y culture, Cartagena 1994, extra de Biblioteca básica murciana, pp. 489-502. En este artículo. la figura de la Potnia Hippon o Tanit, p. 501 ańn está representada siu la serpiente, a la que la diosa sujeta con la mano derecha, que nosolros identificamos en una inspección personal de la pieza, en el Museo de Elda.

51 GARCIA Y BELLIDO, M". P.: "Lueyendas e imágenes púnicas en las monedas libiofenicias", Studia Palaeohispanica, Actas del IV Coloquio sobre lenguas $y$. culturas paleohispánicas, Veleia 2-3, 1987. pp. 499-519.

52 BARRIO Y FERNAVDEZ DE. LUCA, CI. A.: "Protolistoria melillense: Flinicios y Cartagineses", Aldaba 5, 1985, pp. 11-21.

53 Sobre los mitos y la creación de imágenes-arquetipos efr. CI IOISY, M.: "L archétype des trois S.: Satan, Serpent, Scorpion", Euades Cormelitaines 1948, pp. 442-451. Para los psicólogos, todos los mitos son verdaderos, 110 solo mitológicamente sino también histórica y untológicamente.

54 KIRK, G. S.: EL mito. Su significado y funciones en la Antigüedad y olras culturas. Ed. Paidos Studio básica. Barcelona, Bucnos Aires, México, 1970; id.: La naluraleza de los mitos griegos. Ed. Argos Vergara, Barcelona 1984.

55 En 1973, recibió el premio Nolvel en Fisiología y Medicina un grupo de tres estudiosos de ecialogía, ciencia que tiene por objeto el estudio del comportamiento de los animales: Konrard Lorenz, Niko Timbergen y Karl von Frich, este último el primero en ganar notoriedad en todo el mundo por su descubrimiento de la "danza de las abejas", por la que comunjoan a sus compañeras la situación de los objetos que desean.

56 DAMS, LYA R.: "Abejlles et recolte de miel dans l'art rupestre du Levant espagnol", Homenaje a M. Almagro, Madrid, Ministerio de Cultura, 1983, t. 1, p. 363-369; 1ambién FERNANDEZ URIEL, P.: "Algunas anolaciones sobre la abeja y la miel en el muudo antiguo". Espacio, Tiempo y Forma, serie II, 1, Homenaje al profesor Eduardo Kipoll Perelló, Madrid 1988, p. 185-218.

57 BILLIARD,-IAFAYE, en DAREMIBERG-SAGLIO-POTTIER:

Dictionnaire des Antiquités grecques et romaines, s. v. mel, 1. III, 2, 1.

58 EBELIING, E., art. "Biene" en RLA II, 1938. p. 25, cit. por VON SODEN. W.:

Introducción al Orientalismo Antiguo, Ed. Ausa, Sabadell 1987, p. 114.

59 Hist. Aug. III, Ant. P'ío. Todos los documentos han sido reunidos por DEONNA, W.: "L"abeille et le roi", Rev Belge d'Arch. et d'Histoire de I'Art XXV, 1956, p. 105-131.

60 COOK, op. cil. p. 3.

61 COOK, A. B.: "The bee in Greek Mithology", JIIS 1985, p. 1 ss.; sobre Zeus Cretagenes efr. COOK, op. cit. p. 3; también para los personajes divinos relacionados con la abeja cfr. GRIMAL, P.: Diccionario, cil., 95 a.

62 GRIMAL, P. Diccionario de Mitología griega y mmana, Ed. Paidos, Barcelona-Buenos Aires 1982, 16b.

63 COOK, op. cit. p. 8.

64 OV. Fast. V, 20 s.; CIL I, 603; VARRON, L. L. V, 74; VII, 45; R. r. I. 6; PLIN. N. H. XVIII, 29, $284 \mathrm{ss.}$

65 PIJINIO XXIX. 76. 
66 Sobre el uso de la miel womo antisépuico, clir. I.ucrecio II, 886; Columela. RIR, XII, 4.5: Plinio, NH XXIII 108; Phorph. De antmo "umph 15: La miel purifica y cousterva: KRALSE. B. M.: Iuppiler Optimus Maximus Suturmus. Mainz an Rhein 1984. Ph. von \%abern; Sobre Saturno en Hispania efr. BI.EC.H, M.: "Saturn in I lispanien" . MM 19 , 1978, рр. $238-250$.

67 PIINIO, NII, VII, 197. Cir. otros llsos en (ill., L.: 'Perapeia. La merlir:ina propular an ef munclo clásico. p. 99, 362.

68 VARRON. Ap. No Mac. 2:3-26.

69 POYATO HOLGADO. C.-VA\%OLIF,

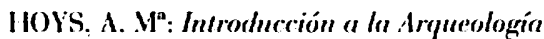
****. El mundo egeo. Ed. Rammin Areces. Madricl, 1991.

70 JliNOl. Ilell. V, 3, 19; DIO|). Slc:. XV, 93; FI. AVIO JOSEFO, Ant. Iud. XIV. +-?; SlAAC. Sile. III. 2: Q. CUURC:I0, Alex. X, 101.

71 GII., L.: Therapeia. La medicina popular en el mundo clásico. Ed. Guadarrama, Madrid $1969, \mathrm{p}$.

72 PI.INIO, NH, XXXIl, 137.

73 (ill., op. ci1. p. 37 ?

74 Textos de magia en papiros griegros. lid. Grodos, 1987, p. 35, 53, papiro PI.

75 Textos de magia cit. p. 5.3 n. 2.

76 FFRNANDEZ URIEL, P': "Alyumas anotuciones sobre la abeja y la miel en el mumlo aniguo", Espacio, Tïmpo y Forma Facultad de Geografía e I listoria, Madrid. UNED, Serie II, 1. 1988, /lomenoje al profesor E. Ripall Pevelló. p. 185-208.

77 I.L CI.AY, Salume africain, Paris 1966, p. 151: también VON BERNIIARD NEUTSCH: "Tas Ninphas emi Iliaron. Zum unterirdischen Heiligtum ton Puestum. Ileidelberg 1957 (Abhandl. A. I leidelloerg. Akad. d. Wissensch. Phil. I list.. KI. Juhrg. 1957. 2 Abh.): PICARD, (h.: Ephese el
C ilaros p. 18:3; SESTIERI, P. C.: "I de petit temple semterrain de Paestum", Re" Frangarise fev. 1955; ROI.LEY, (I.: Les l'ase's de bronze de l'archaisme rícent int Grand Grèce. Bibliothèque de l'Institut Français de Naples. Ile. Série. vol. V. Pub. du (iontre J. Bérard, Naples 1982. Iere. partie: llydries et amploores. Phacsium, Sala Comsilina, descriptim, p. 15 ss.

78 IBL IRN. I..: "I loney pots. Tree while-gromud cups by Sondes painter". Anlike Kmmst. 28, 1985, p. 9:3-105.

79 Inscriprion. (IS I, 3, n" 166, lít. 8; estelas cfr. IJ. (;I.AY. M.: Sat. Afric. Mon. I. p. 291. n" 1 (Beja-Le Kef). p. 308 y ss. n. 2 y $X,+$ (Ilr. es Srira); Estela de Kleneliela panal sobre plato, Sat. Afric. Mon. II. Kemelieln 4 y pl. XXIX; Del misımo lagar n" 15: De: Djemila en la mano. II. Djem. 15, 22.; Djemilu 30. pl. XXXIV, lig. 3; De I.ambersa II. Lamb. 51; De Sillegre. 2, 4. 14, 20. 23. pl. XXXV, lig. 5 y 6.

80 K. WYSS. Die Milch im Kult der Griechen und Römer, Religionsgeschichle lers. u. formb. XI. 2, Giessen 1914, p. 12.

81 VAZOUHZZ IOOYS, "La miel Alimentu de: ererisiclud...

82 LE (iLAY. M.: Saturne africain, París 1966. passim.

83 ( IS I. 3, ॥" 166. I. 8.

84 Otros texios del Antiguo Testamento que mencionan la miel son Ex. 3. 8; 16. 31: Dt. 8. 8; Juce 14. 8; 1S. 14. 25; Sal. 19. 10; 81. 16; 119. 103; Pr. 5. 3; 16. 24; 24. 13; 25. 16; (ant. 4. 11; Is. 7. 15; Ea. 3. 3: Mt. 3. 4; Mr. 1. $6 ; A_{p} .10 .0$.

85 Cifr. Ide Clay p. 389 y nota t. 5.

86 HIEROI)OTO II. 40.

87 llliR(O)OOTO $+.19+($ p. 435$)$ se refiere a la ahundancia de miel en la zona de los Gizmutes en Libia 
88 LE CALY, op. cit. lám. XXXIV, 3.

89 LE GALYA, op. cit. p. 390: "Certes, le culte de Saturne ne saurait être consideré comme un véritable culte à mystères. II comporte cependant, on lá vu, des cérémonies d'initiation ou micux, si l'on veut, d"introduction", parachevant en quelque sorte lá consécration à la divinite ${ }^{\prime \prime}$.

90 LE CL AY, op. cil. p. 389: también SALUST. phil. De diis et mundo, 4; USENER, "Milch und Honig", Thein. Muse. LVII, 1902, p. 177 y ss.; BOYANCE, P.: "Sur les mystères plırygiens: "J'ai mangé dans le tympanon, $j$ "ai bu dans le cymbale", R. E. A. 1935, p. 161-164, explica esta fórmula, palabras de rito de paso pronunciado por los iniciados, por una alusión a la comunión mística, ceremonia en la que tomaban vino, leche y miel.

91 VERMASEREN, M. I.: "Les inscriptions sacrées du Mithraeum de Sainte Prisque sur l'Aventin", en Religions de Salut, Bruxelles 1962, p. 69-70; verso IV, 11;

VERMASEREN, M. J.-VAN ESSEN, C. C.: The Excanations in the Mithraenm of the Church of St. Prisca in Rome. Leiden, Ed. Brill 1965, p. 207-211;

92 BUFFIERE, F.: Les mythes d'Homére dans la pensée grecque. París 1956, p. 605.

93 Agradezco al Dr. D. Julio Muñoz, colaborador del Departamento de Prehistoria e H"Antigua, UNED, sus indicaciones al respecto. Cfr. MUÑOZ CARCIA-VASO, J.: "El culto de Mithra en Hispantia". Tesis doctoral inédita. Medrid, UNED, 1990.

94 TERTULLANO, De comona, 3 (C. S. E. L. t. LXX, p. 158) y Adv. Marcion 1. 4, (llid. t. XLVII, p. 308): también sobre este tema $\mathrm{Y}$. DUCHISNE: Origines du culte chrétien, París 1909 , p. 322, 338, 341, sg. cit. por LE GLAY, op. cit. p. 389 n. 5.
95 CURTOIS, C.: "Sur le baptistère découvert dans la région de Kélibia (Cap Bon)", Karthago VI, 1955, p. 119.

96 FEVRIVER, P. A.-POINSSOT, C.: "Les rierges et l'abeille. Note sur l'iconographio du haptistère découvert dans la région de Kélibia (Tunisie)" Cah. Arch. X, 1959, p. 149-156.

97 Cir, supra, notá no

$98 \mathrm{PLANT}$, Greek coins topes and their irlentification.

Ed. Seaby, Londres 1979.

1. V" 1118: Tarra: en Creta. Cabeza de cabra / abeja; 2. N" 1484: Efeso, en Jonia. 387-295 a. C. Ciervo y palmera/ Abeja; 3. N*1686, de Melitae, en Tesalia. 350 a. C. Cabeza de Zeus/Abeja. AE 14-15; 4. N" 1687, de Julis, en la isla egea de Ceos. S. III a. C. Cabeza de Zeus (O Aristeo) / Aheja; 5. $N^{\circ} 1688$, de Julis, en la isla egea de Ceos. $S$. III a. C. Cabeza de Apolo (o Aristeo) / Abeja. AE 11. 6. N" 1689, de Praesus, en Creta. 300-200 a. C. Caheza de Perséfonc/ Aheja. Hemidracma. 40 gm. AR $13 ; 7 . \mathrm{N}^{\circ}$ 1690, de Elyrus, también en Creta. 400-300 a. C. Cabeza de cabra y lanza / Abeja. 78 grm. (Dracma). AR 21: 8. N 1691, de Lisus, también en Creta. 400-300 a. C. Abeja / cabeza de cabra: 9. N" 1692, de Efeso, en Jonia. 280-258 a. C. Ciervo/ Abeja; 10. N" 1693, de Arados, en Fenicia. 174-118 a. C. Cierva delante de palmera / Abeja (copiado de un tipo de Efeso). $63 \mathrm{gm}$ (dracma). AR 17-18; 11. N" 1694, de Esmirna, en Jonia. Epoca imperial romana. Delfím/ Abeja.

99 Cfr. VAZQUEZ HOYS, A. M", artículos sobre el culcoa a la serpiente cit. en Bibliografía.

100 En WILL, E.: "Sur la nature de la mantique pratiquée à l'J leraion de Perachora", R. H. R. 1953, p. 157 y n. 2 , se resumen numerusas referencias. 
101 Para DliL.COLIRT, M.: Les grmules sanclunims de la Grèce. P. II. I.. Paris 1947. p. 118. 121. los misterios cle likeúsis estau asociados a un culto agrario Intis arraico del conocido en époça clásica. Sobre las diferentes sacerdotisas llamadas Melissar, Zeus Meliteus, Melisson̂os, ntc... "fr. (.OOK, "The bee in Grenk Millaulogry" vit. p. 3 .

102 DI:I COURT, op. cit. p. 126.; p. 1:32; p. 133: kelen̂tan= morir: teleish/hai (ser inicialo). (LMONT, F.: Mon. m)st. Mithrae p. 320) (COOK.: "The lee: in Creek Mythologie:" JHS XV, 1895, 1-24: (BAll,OT. H.: Le culle de (ybile p. 182. 252 (sobre las Melissai).
103 Para la ascriaución entre la mujer y las alejas efr. D):TIE.VNE. M.: "The Myth of I loneyed Orphens" in R. L. CORDON (ed.): W. Religion and sociely: 1981, p. 95-110.

104 (.Fr. BL RNS. Honey Pots” cir.p. 95) y u. 1:3.

105 (.fr. tambien solore la miel BII.I.JARD). R.: "Votess sur l"alseille et l'apiculuure daus l'Autiquite", en Bull. Sor. Centrokes d'Apicullure el hasectologie, París 1900. p. 1-110.

106 VA\%(Q) H. IIOYS, A. M": "Aspectos mágicos cle la Antigüedad II: los esprejus mágicos". Bolesín de la Asociación de Amiges de la Arymeologia 20, Dic. 1083t. PII. 18-224. 
Además de la citada en notas, se lai comsultado la bihliografía siguiente:

A. A. V. V.: La colonización fenicion en la Pesninsula llérica. 100 años de invesligación. Aclas del Seminario. Almería, j-7 Jumio 1990.

I Jornadas de Arqueologín de Melilla. Melilla, (0-9) abril 1987

ALBIET SEMLER, M" E.: Tiro $y$ las colomies fenicies te Occidente. Ed. Bellaterra, Barcelona 1987

B.IRIRIO Y FERVANDEZ DE IUCA, CI. A.:

-Protohistoria melillense: Finiciosy

Cartagineses", Aldaba 5, 1985, pp. 11-21.

Id.-FONTENLA, S.-DIAZ SANCIHEZ,

J.-MONTOYA. R. M.: "Las momedas carlaginesis extraídas del puerto de Melilla". Tripmene 1, Einero 1987, pp. 37-39.

B1.AZQUEZ, J. M": "La aculturación en la religion indigena" Formas de difusión de las religiones antiguas, Segundo encuentro-coloquio de Arys, Jarandilla de la Vera, Diciembre 1990. pul. Maudrid 1993, pp. 35-74.

CAI.DERRON RUIZ. L.-PONCE G'Giliz, A. A.: "Itinerario místico mágico por lkelaia: Morabos, leyendas y tradiciones populares".

CORRAL, CAÑON. M.: "Fil lironec Carriazo en el ambito de las relaciones extrapmininulares". B.AA 18, Dic. 1983. pp. 19-25.

CIILICAN. W.: O comércio martitimo. Eid. Verbo. Lisboa 1966.

(IIARLES PICARD, G.: Les meligrions de Pilfrigues Anlique. París 1954.

DEL. OI MO LETL, C. dEI-ALIBIET SLEVILER. Y" li.: Los fenicios en la Peninsula Béricu. Ed. Ausa, Saloadell 1986, 2 vols.

DE:VER, W. G.: "Asherah, Consort of Yahweh?. Now Evidence from Kuntillet Ajrud", Bulletin of the American Schools of Orientl Researeh 255. 1984, pp. 21-37.
FERNANDIZZ, DE: GASTRO Y PEDRERA, R.: "Las necrópolis púnica y romana de Melilla", Aldaba 9, 1987. [1]. 127-134. (id. en Africer. Madricl. Junio 1950, n" 102, pp. ?-11 (257-201).

FERNANDIZ\% MIRANDA, M.-RODERO, A.: "EI Círculo del listrecho veinte años después", II CIEC, Madrid, LINED 1995, pp. 3-20.

HERNA.VIJIZ, IRIEL, P.: "La evolucion mitológiea de un mito: La abeja", formess de difusión de Ins rreligiones antiguas, Segundo rncuentro-rofoquio de Arys, Jarandilla de lin Veria. Diciemlore 1990, pub. Madrid 1993. p. p. $133-160$.

ld.: ". Vuevas aportaciones sobre la appiculura en la antigua I lispania", II Congresso de Ifisteria Anliga. Coimbra 1993, pp. 955-69.

GONZAI I:Z PRA'TS, A. "La presencia lenicia en el lovante peninsular y su influencia en las comunnidudes indigenas", $L-I V$ Jornorles de" Arqueslogún fenicion-púmica (Ibiza 1950-59). Ibiza 1991. p|p. 109-115.

GoNYAl.NES GRAVIOTO. E.: EGonomía de la ciudad antigun de Rusadir". Aldaba9. 1987, pp. 97-120.

II.: E.: "I al descripción de Yauritania Tingitana en Pomponio Mela", II CIEG, Madrill, LNED 1995, 1. II, .21. 259-265.

(; TERRRERO AYLSO, V.: Narios y maregantes en las rutas de Baleares durante la prehistoria. E. EI Tiall, Pallma de Mallorea 1993.

I.Li GLAY. M.: Saturne africaine. Monuments. I. Afrique proconsulaire. Paris 1961.

Id.: Sarume africain. II. Monumentes. Numidie-Mourélanies. Paris 1960.

Id.: Saturme africain. Mistorie. París. B. L.. F. A. R. t. 205, 1966.

LIPINSKI, F:.: "Tannit et Ba`al Hamon". Itamburger Beilräge zur Archäologie 15-17. 1988-90), plp. 209-249

L.OPI:Z (AASTRO, I. L.: Hispania Poena. Los 
fonicios cu la Hispania romana. lisl. Cirition, Barcelona 1994.

MARIN CEBALLOS. M". C.: "Reflexiones en torno al papel econónico-politico del templo fenicio", Homenaje a Jose .M" Blazquer II. Maadird 1993. pp. 349-362.

Ifl: "Dea Coelestis en la epigrafia hispana", II Congresso Peninsular de llistoria Artiga, Coimhra 1993, pp. 825-845.

Id.: "La religión fenicio-púnica en lispaña (1980-1993), Hispania Antriqua XVIII. 1994. 11p. 5333-568.

Id.: "Dea Caelestis en un santuario ibérico", Coloquio de Cartagenas 1.61 mundo primiro. Historia, sociedad y culturn. Murcia 1994, pp. 21:3-22:5.

Itl.: "I as relaciones entre Isis y Astarté: Apumtes para su restudio", Anna Maria Bisi: in memoriam. Iin prensa.

Id.-J.OMAS, F. J.: "Cádiz fenicion-púmico y: romauno", Dialoghi di Archeologia, Tierza Serie. anno 10, 1992, n" 1-2, pr. 129-14:3

POSAC MON, C.: "Las perspectivas arqueoligricass de Melilla", Aldaba9, 1987, pp. $121-120$.

POVIDDA NAVARRO, A.: "luno Cuclestis en la colonia hispanorromana de Ilici". Lispocecio. Tiempo y Forma, serie II, If" Antigual, 1. 8, 1995, pp. 357-369.

RIIS, P. I.: "Plaquettes syriemuns d Astarté dans des milieux grecs". Mélanges dr Minirersile Srainl Joseph de Beyrouth XXXVII, fass: 8, 1960. pp. 193-198.

ROJ)RIGLLIZZ MART'INEZ, J.: "Oeranngrafia del Mar de: Alborán", Aldaba 13. 1989, pp. 71-77.

RI T\% DF: ARIBLLO, J.: "Rutas marítimas y colonizaciones en la Peninsula lhérica. Lina aproximación náutica a algunos problemus", Hélica 18, Roma 1990, pp. 79-115.
SARO GARANDILLAS, F.: "Melilla. Cien aĩus de hallazgos arcpueológieos", Aldaba 13, 19889, pp. 77-84.

VAZOU T:Z IOYS, A. W": La religión romama on Hispomian. Fuemess epigráficas, arqueologices.y. mumismátiras. Madrid, Noviembre 1974 (Servicio de publicarciones de la liniversidad Compluanse 1982). 2 tomos.

ld.: Al mmelos griego. De los inicios a la conquista romana. 2"parte: Crecia descte al sigho IV. Alejamelro Magno. El helenismo. (a: 118. (NF.D. Madrid 1994.

Id.: Diana on la religiosidad hispanorromana. Tomo I. Las ginenles. Las diferentes diosas. Madrid. (Nl:D), col. Aula Abierta. 1995.

Id.: Diana en to rrligiosidad hispanorromana. T'umo II. Romma. Cuenen y Segóbrigat. Mardrid, INIII), 199) (IIN PRENSA).

lal.: Diccionario de Términos histórices. I.

Próximo Oriente. Egapto, Grecia y Roma.

Madrid. Fal. Alianza. Madrid 199+ (con P. Fernamde\% ( riel).

Id.: Dircionorio de simbolos y términes mágicos. Malrid.

Universidard a Distuncia 1993.

Id.: Diccionario de magia en el mumblo antigno

Folicorial Adderaban, 1995.

Id.: Trirminos de magia ve religión en el mumdo antigue, Madrid, UNED, (con O. Muñoz Marrín).

Id.: Los ricios rlioses no han mmerto. (Gon M" Tiresa Conzálex Rumán). Ed. Aguilar, Madrid 1990.

BIR I ROWO, M.-VAZQLEZ HOYS, A. M": "The representation of serpent in Ancient Iberia", International Conference on Archacologr and fertility ('ult in Ancient Mediterramean. Maltit. 2-5 Septicmbre, 1985, ed. Malta 1980. pp. 305-314.

VAZQLEZ HOYS, A. M": "From earth lieaven: The snake and the indoeuropean 
religious change", The Transformation of

Luroperau and Anatolian cullure, 4.500-2.500 B.

C.. organized by the ludo-liuroprean Suculies

Program. I niversity of California, Los Angeles

in conjunction with University College. Dulshin. 15-21 Sep. 1989. En prensa.

lal.: "Los cultos a la serpiente en Ilispania", I"

Cologpuio Gataico-Miñoto. Lugo (Galicia).

24-27 Septiembre 1990. En prestsa

If.: "lil comercio entre Hispanin y Manritania y

el templo de Hércules-Melkarl en (Cades. (") Épocia de luba ll y Ptolomeo". II, Congresso EI

Fistrecho de Gibraltar: Ceetua, Novimbre 1990.

Id.: - I it miel, alimento de eternidatl". Ilomenaje a .M. Ponsich.

Liniversidat Complutense. Madrit, 19(2). pp.

$31-47$.

Id.: "Aquella que ama el silemcio: I.a serpiente

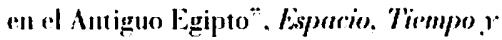

forma. Serie Il (Historia Antigua). n" 4. Madrid 1991, I NEDD. Departamento de Prehistoria e. 1 listoria Autigua, pp. 37-72.

II.: "Mlgunas consideraciones sobre Silvano en I lispmuia", Espeacio, Tiempo y formm, seric II, "I" 4. Matride 1901, pp. 107-1:30.

Id.: "Aplicación de las hases de datos a las nerópolis del Minoico Reciente en el área de Knosions". Il Congresso Internazionale di Nicenologia. Roma-Yápoles. 1+-20

Ortubre 1991. Instimo per gli Studi Mirenei ed ligero-Anatolici del CNR.

Id.: "Apruxinnación a la serpiente como motivo religioso y mágico en el Próximun Oriente y

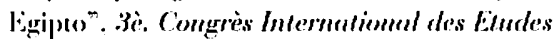
Phénicienness ef Puniques. Thíne\%. 11-16

Nowembre 1991. Centre d'Etudres pheniciennes "l puniquess ox des Antiquités libỵun's. Ministére des Affaires Culturelles. Institut National d'Areheologie et d'Art.

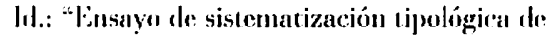
ammletos Rálicos en Hispania", II/ Congreso dr Anss. Jarandilla. Dic. 1991, con Del I loyo Callojin. J. Madrid 1994.

ld.: "lil templo de Heracles Melkart de Gades y su paper enconónico". Estudis allistoria Economica, ticonomia y societat en la Prehistoria i món antic, Palma de Mallorma 190:3, 1. 1. 91-112.

ld.: "I a serpiente en el Egipto Antiguo", Aregpriaca (omplutensia I, Alcalá de I lenares 1992. pp. 9:3-113.

ld.: "La serpiente en las monedas griegas" Espacio, Thempo y. Forma, serie II. H" Antigua. Madrill. (NEDD, 1994, $\mathrm{n}^{\circ}$ 5. pp. 59-98.

Id.: "I a religiosidad romana en Hispania y sil investigación", I Simposio Nacional de Cionrias de las Religiones. (SECR). Madrid, 6-7 Ochubre

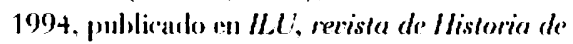
less rrligiomes. 0. 199.5. pp.

Id.: "Scepiente y Atis en una mueva lápida sepulcral extremeña". Ilomenaje a Schubart. Madrid 19).j. págs. 245-250. Con Julio Muño\% y Carmen Povalo.

Icl.: "Incidencia de la religión lenicia y púnica en el paurrama religioso del SE. peniusular" + Congreso Internaciomal de Eslarlios finmicios. Cádiz. Octulbre 1995. Con Antonio P'oveda Navarro.

Ihl: "l a sorpieme en la cerámica iberica de Virlie:" congreso Nacional de Arqueologian. Eilohe, 8-11 Marzo 1995.

kl.: "L a magia de la palabra". Sipencio, Tiempo

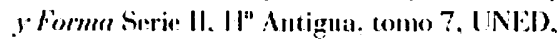
Madrid $19 \% 4, \mathrm{pp} .307-34$ ?

ld.: "I.a serpiente en la epigrafía lispana".

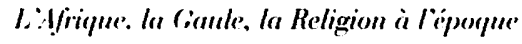
romaine. Málanges à la mémoire de Marrel lee Glay, Lalomus. Bruxelles 1994. pp. 5688-582. 